\title{
VIEWS OF ADDICTION AND THE DUTY TO WARN
}

\author{
Alan Schwartz*
}

You will come first of all to the Sirens, who are enchanters of all mankind and whoever comes their way; and that man who unsuspecting approaches them, and listens to the Sirens singing, has no prospect of coming home and delighting his wife and little children as they stand about him in greeting, but the Sirens by the melody of their singing enchant him. They sit in their meadow, but the beach before it is piled with boneheaps of men now rotted away, and the skins shrivel upon them. You must drive straight on past, but melt down sweet wax of honey and with it stop your companions' ears, so none can listen; the rest, that is, but if you yourself are wanting to hear them, then have them tie you hand and foot on the fast ship, standing upright against the mast with the ropes' ends lashed around it, so that you can have joy in hearing the song of the Sirens; but if you supplicate your men and implore them to set you free, then they must tie you fast with even more lashings. ${ }^{1}$

7 HIS Article asks (i) whether tort liability should be imposed on 1 the makers of substances that are legal to sell but that may addict users, if the makers have not warned users of the risk of addiction, and (ii) whether the state should create a standard warning against addiction that the makers of possibly addicting substances must give. There is little authority on the first question. ${ }^{2}$ Recently, plaintiffs

* William K. Townsend Professor of Law, Yale Law School. This Article was improved substantially by comments made at a Law and Economics Workshop at the University of Chicago and Faculty Workshops at Pennsylvania, Tulane, and Yale Law Schools. Robert A. Burt, Jules Coleman, Richard Craswell, Will T. Jones, Michael Levine, Stephen J. Morse, Jeff Strnad, and Cass Sunstein also made helpful suggestions. This Article is partly based on a report I made as Associate Reporter to the American Law Institute Project: Compensation and Liability for Product and Process Injuries. The thoughts expressed here are mine, and reflect neither the views of other reporters on the project nor the views of the ALI.

1 Homer, The Odyssey, bk. XII, 11. 39-54 (R. Lattimore trans. 1967). The speaker is Circe.

2 It was held, in Crocker v. Winthrop Laboratories, 514 S.W.2d 429 (Tex. 1974), that the maker of a drug must warn against the drug's propensity to addict some users if the maker knows or should have known of this propensity. See also Bikowicz v. Nedco Pharmacy, 130 A.D.2d 89, 517 N.Y.S.2d 829 (1987) (cause of action against drug manufacturer and medical intermediaries upon whom patient relied for failure to warn of the addictive properties of Talwin). But see Pysz v. Henry's Drug Store, 457 So. 2d 561 (Fla. Dist. Ct. App. 1984) (where prescribing physician knew of amount of drug prescribed over a number of years and patient's 
have added a cause of action, in their suits against the cigarette companies, which claims that the companies' warnings always have been defective because the warnings do not caution against cigarettes' addictive properties. Addiction is a distinct harm on this view because consumers may know that long-term smoking can cause disease, but not know that the decision to begin smoking necessarily entails an irrevocable commitment to smoke long term. No cigarette case has been won on this ground, ${ }^{3}$ but the chance for success was improved by the recent Surgeon General's report concluding that

history of addiction, pharmacist's failure to warn of addictive qualities of drug not failure to exercise due care). There seem not to be other cases. It is becoming customary in the mental health literature to replace the word "addiction" with the term "dependence." This Article uses the more familiar word.

3 A thorough argument that the cigarette manufacturers should be held liable for failing to warn against addiction is in Garner, Cigarette Dependency and Civil Liability: A Modest Proposal, 53 S. Cal. L. Rev. 1423 (1980). There is no legal impediment to the argument as applied to pre-1966 sales, but a question exists whether a warning claim for sales made after 1966 is preempted by the required Federal Warning. The statute explicitly provides that "[n]o statement relating to smoking and health, other than the statement required by section 1333 of this title, shall be required on any cigarette package." Federal Cigarette Advertising and Labeling Act, 15 U.S.C. $\S 1334$ (1982) (Labeling Act). In subsequent legislation relating to smokeless tobacco products, Congress made explicit its intention that "[n]othing in this Act shall relieve any person from liability at common law . . . to any other person." Comprehensive Smokeless Tobacco Health Education Act of 1986, § 7(c), 15 U.S.C. § 4406(c) (Supp. IV 1986). This suggests a congressional policy in the context of tobacco products labeling not to preclude civil liability. See Palmer v. Liggett Group, 633 F. Supp. 1171 (D. Mass. 1986). All agree that the Labeling Act prohibits state legislatures and agencies from requiring additional warnings. The legislative history suggests that this was Congress' primary concern. S. Rep. No. 566, 91st Cong., 2d Sess. 12, reprinted in 1970 U.S. Code Cong. \& Admin. News 2652, 2663. The court in Palmer has held that the statute does not preempt common law tort suits based on the inadequacy of the warning. 633 F. Supp. 1171. Two other courts have found preemption, one on the ground that the congressional scheme requires uniformity of labeling, Roysden v. R.J. Reynolds Tobacco Co., 623 F. Supp. 1189 (D. Tenn. 1985), and the other for no discernable reason, Cipollone v. Liggett Group, 789 F.2d 181 (3d Cir. 1986). These cases considered warnings against the dangers of cigarettes in general, not the danger that cigarettes addict. Congress apparently did not have this danger in mind. Thus, the question whether the federal law preempts a common law holding that cigarette warnings that fail to mention addiction are defective seems to be open. The Alcoholic Beverage Labeling Act of 1988, Pub. L. No. 100-690, $\S 8001,102$ Stat. 4518, 4519, requires firms to warn that "[c]onsumption of alcoholic beverages ... may cause health problems" and contains a preemption statement similar to that in 15 U.S.C. $\S 1334$. Again, Congress seemed not to consider addiction.

This Article will not deal with the preemption issue. Many cigarette cases are brought by persons who smoked extensively before 1966 and many more alcohol cases could be brought by persons who drank before 1988 . Thus, the argument here will be relevant to a large number of cigarette and alcohol cases, and to many actions that could be brought in connection with other products. 
smoking is addictive, particularly since the report recommends that the tobacco companies be required to warn. ${ }^{4}$ The consequences of a plaintiff's victory likely would spread beyond the tobacco industry. Alcohol also is said to be addictive, yet the liquor and wine makers do not warn against the risk of addiction. Drugs that reduce stress, such as valium, sometimes are abused and so may be found addictive; the drug makers, however, do not advise consumers of their products' possibly addictive properties. The question whether warnings in common use are legally infirm because they fail to caution against a product's propensity to addict thus is open and topical. It also is important because an affirmative answer could generate products liability litigation that would match in magnitude the asbestos and DES cases. The question whether the FDA or some other agency should create standard warnings for possibly addictive products also is significant because many substances can be abused.

The question of what duties firms should have to warn against the addicting properties of their products is clarified when a distinction is drawn between what an addiction is and what the cause of an addiction is. The two central criteria that define an addiction are: (i) addicted persons manifest "excessive appetitive behavior"- they consume drugs, alcohol, or tobacco to the point where consumption impairs normal functioning or endangers health; (ii) this excessive appetitive behavior is very difficult to discontinue. What this Article calls a "view" of addiction is a causal explanation of addictive conduct. ${ }^{5}$ Three causal views play a role in current discourse. Perhaps

4 Office of Smoking \& Health, U.S. Dep't of Health and Human Services, The Health Consequences of Smoking-Nicotine Addiction: A Report of the Surgeon General (1988) [hereinafter Nicotine Addiction]. This report obviously would answer "yes" to the question whether the state should create standard warnings against addictive products.

5 The text distinguishes the question what is an addiction from the question what is a cause of an addiction to avoid begging questions. The two-part definition of an addiction captures what is uncontroversially central to addictive behavior-its excessive and compulsive aspect. The Article then inquires into the causes of such conduct. As an illustration of the danger to be avoided, defining an addiction as excessive appetitive behavior accompanied by substanceinduced chemical changes in the brain conveys the impression that addictions are caused by the consumption of addictive substances rather than caused by "psychological" or other factors. Some commentators, however, would claim that the issue is whether substances or psychology play the major role. The Surgeon General's report on nicotine addiction seems to beg questions in the way sought to be avoided here: it claims that nicotine is addicting on the basis of "pharmacological" analyses, but the report explicitly eschews consideration of "psychological and social factors" that, the report itself concedes, "also are important influences on tobacco use." See Nicotine Addiction, supra note 4, at 6. Thus the authors of 
the most common is referred to here as the "strong substance caused view" (SSCV), which holds that certain substances can addict ordinary persons. According to the strong substance caused view, some substances induce excessive appetitive behavior in ordinary users in two related ways: first, consumption is initially pleasurable, but the pleasure declines with time so a user ultimately would prefer to stop; second, consumption, however, induces physiological changes in users such that withdrawal would create severe physical pain or discomfort. A user is "hooked" when the negative utility she would derive from withdrawal will exceed the negative utility she expects from continuance. An "addictive substance" is a product that can hook any ordinary person in this way. The Ulysses legend is metaphor for the strong substance caused view of addiction; anyone who hears the Sirens' song is lost unless he takes extraordinary precautions.

The SSCV holds that an addictive substance can hook (almost) anyone who consumes a nontrivial amount of it. A second view, called here the "biological view" (BV), claims that only persons with particular biological predispositions will become hooked; the remainder can consume the substance with impunity. For example, only a subset of alcohol users become alcoholics. According to the BV, this subset is composed of persons with a genetic predisposition to alcoholism. These two views of addiction are similar because they suppose addiction always to have the same phenomenology-in particular, they suppose addiction to be largely involuntary-but differ in that the SSCV holds that addicting substances can hook almost any ordinary person, while the BV holds that these substances only hook people with certain biologies.

A third view of addiction, referred to here as the "characterological view" (CV) has two aspects. Respecting the excessive appetitive behavior facet of addiction, the $\mathrm{CV}$ holds that addicts consume to excess because, given their characters and circumstances, excessive consumption reflects the best adaptation they can make to life; excessive consumption, that is, provides addicts with more utility than any other mode of use or abstinence. This view thus claims that the predisposition of some persons to engage in addictive behavior is more a

the report cannot distinguish the relative causal contributions to long-term cigarette consumption of nicotine-induced biological changes and the "psychological and social factors." 
function of their characters than of their biologies. Respecting the hard-to-stop facet of addiction, the CV holds that users continue not because consumption is the lesser of two evils, as the other views of addiction claim, but because heavy consumption is utility maximizing. Another way to put the CV's claim here is that an addictive behavior is difficult to discontinue given one's character; hence, the best way to stop is to alter one's character. Stopping then actually is very difficult because character change is very difficult.

These three views of addiction imply different legal rules respecting warnings. The SSCV implies that makers of addictive products should warn that the pleasure use provides will decline over time, but physical withdrawal cost will increase so that there is a "great risk" of addiction. Circe was right to warn Ulysses because Sirens were bad for sailors. The BV implies a similar warning but qualified by the word "may"; that is, the warning should say that people with particular biologies will become addicted with a high probability. The CV does not support a case for warnings, given the conventional understanding of the function that product warnings serve. According to the $\mathrm{CV}$, addicts consume as long as consumption yields gains in excess of the (often high) costs, so there is no danger to be warned against. Another way to put this conclusion is that, on the CV, withdrawal cost is not primarily physical, but rather is an opportunity cost-the foregone positive benefits that further consumption would yield. ${ }^{6}$ The conventional understanding of product warnings holds that persons should be warned against risks. A risk is commonly defined as a possible outcome arising from use itself that would decrease a person's utility were it to occur. That a person might incur an opportunity cost from discontinuing use is not a risk in this sense; an opportunity cost could arise from discontinuance only if use itself

${ }^{6}$ Observers who believe that the existence of physical withdrawal costs do not fully explain addictive behavior commonly say that addiction has a "psychological" component, or that some addictions are "psychological." This sometimes means that to discontinue excessive appetitive behavior would cause mental pain. The CV holds that this mental pain is the opportunity cost of foregone utility. On this interpretation, to say that an addiction is psychological is to adopt the CV. Another interpretation of the claim that addictions are psychological is that people with neuroses or other mental disorders are more likely to become addicted. This claim is consistent with the $\mathrm{CV}$, which does not claim that addicts typically are mentally healthy and happy persons, but only that addictions reflect the best adaptations for addicts given who they are. Other interpretations of the claim that addictions are psychological seem obscure. 
yielded net gains. To make this point more concrete, realize that most people would answer "no" to the question whether the chocolate makers should be made to warn consumers that chocolate is addicting because it is so delicious that many users would incur high (opportunity) costs were they to give it up.

This Article argues that the evidence best sustains the CV; hence, there should be no duty to warn. In particular, the SSCV's focus on substances is plausible because some substances are more likely than others to be associated with addictions, but the central predictions of this theory respecting the nature of addictive behavior are unsupported by the data. The BV also is plausible as a theory of addiction because there is some evidence associating addictions with genetic factors. There is, however, no theoretical account of this linkage and the evidence also suggests that genetic factors can explain only a small amount of addictive behavior. Rather, the CV best accounts for much of what is observed about addictions. To be more precise, widely held conceptions of what it means to act freely together with the evidence imply that addictive behavior is chosen, not compelled.

This is not altogether to deny the common perception that persons experience physical withdrawal costs from discontinuing the use of certain substances. These costs sometimes do exist, but apparently not at levels above those that most people would call an "irritation." " There is a case for state-created standard warnings that discontinuance can cause such discomfort, on the analogy to currently required drug warnings that use can cause irritability or sleeplessness. The question whether addiction warnings of this type should be required seems an unimportant public policy issue, however.

Part I below first states the normative case for requiring warnings and shows that it is best grounded in the SSCV. This Part then shows that the SSCV is likely false. Part II discusses the other views of addiction and argues that the CV best fits the evidence. Part III then shows what rules respecting warnings each view of addiction implies and argues that, given the greater likelihood that the CV is correct, there should be no common law liability for failing to warn of the

7 For example, the chief self-reported physical withdrawal cost from ceasing to smoke is irritability, which declines substantially over a period of three to six months. See Clavel, Benhamou \& Flamant, Nicotine Dependence and Secondary Effects of Smoking Cessation, 10 J. Behavioral Med. 555, 557 (1987). Similar data respecting physical withdrawal costs are cited infra note 18. 
addicting properties of products and few state-created standard warnings. The analysis in Part III initially rests on the conventional view of the purpose for requiring warnings, that is described above. Part III also considers broader theories of the functions that warnings can serve, such as the theory that society should require warnings to express its disapproval with the use of certain products that it is unwilling to ban. The case for requiring addiction warnings by statute or regulation is more plausible under these broader theories, but ultimately is unpersuasive.

Before reaching the argument, two clarifying remarks should be made. First, that substance abuse is optimal for abusers given their characters does not mean that it is optimal for society. Addicts sometimes create negative externalities; a possible strategy for eliminating them is to make illegal the sale of substances whose consumption is associated with highly antisocial conduct. This Article does not consider such prohibitions because its subject is warnings; a discussion about what warnings firms should give presupposes a prior political decision to allow informed use. The political decisions to permit the sale of the products that are discussed below-primarily tobacco and alcohol-are not analyzed here. Second, while excessive appetitive behavior is optimal for addicts, being an addict generally is not a good thing. Addictions often reflect desperate adaptations that are made by persons who hold immature or otherwise unfortunate attitudes or who are in very difficult circumstances. For example, a person is more likely to become addicted to drugs or alcohol, other things equal, if she lives in a social setting so deprived that being an addict is acceptable (or at least not condemned). Consequently, the state has a legitimate role to play in helping addicts to change, in instructing people, especially the young, as to the unfortunate consequences to which the possession of particular characters can give rise, and in ameliorating social circumstances that are so awful as to make addiction seem an optimal response. These state functions are not considered here. This is because the product labels on which warnings must appear are poor vehicles for engendering character change or conveying moral instruction, and this Article inquires into the disclosures that firms should be required to make, given the constraint that the disclosures must appear on the product's label or in accompanying sale materials. Also, no version of Products Liability Law could be constructed that would effect the major social changes that might reduce the frequency 
of addiction in particularly susceptible groups. The price of focusing on warning issues thus is the neglect of important questions respecting how the state should best respond to addictive behaviors. Warning issues are sufficiently significant to justify this constrained focus.

\section{WARnings and the Standard View of Addiction}

\section{A. The Case for Requiring Warnings}

Some products are "unavoidably unsafe," in the sense that any good and harm these products do is a necessary function of their chemical structure; consequently, the products cannot be made safer without also being transmuted into different products. Tobacco, alcohol, and some drugs are unavoidably unsafe. ${ }^{8}$ The argument that the maker of an unavoidably unsafe product should warn of its addictive properties has three steps. First, warnings in connection with unavoidably unsafe products will inform choice. The notion is that a person can be harmed but not wronged by the consequences of actions she voluntarily undertakes-risks to which she consents-so the maker cannot wrong users when it sells an unavoidably unsafe product accompanied by an appropriate warning. Second, voluntariness is not a binary concept but a continuum; some choices are more voluntary than others, for example when made under less financial pressure or with more information. Third, conventional notions of autonomy imply that the more irrevocable a person's decision is, the greater should be the degree of voluntariness required before the state respects the person's choice. Joel Feinberg suggests how these premises may bear on the warning question:

Another example of a harmful choice which for all practical purposes may be irrevocable is the decision to begin taking an addicting drug. If the drug-taker has no idea that the drug is in fact addicting, or if he falsely believes that it will not be addicting in his case, then his decision falls well below the requisite level of voluntariness. ${ }^{9}$

8 Tobacco differs somewhat from the other products listed because the nicotine content of cigarettes can be reduced. Whether cigarettes can be modified sufficiently to pose little risk to health but still be pleasureable to smoke apparently is not known. RJR Nabisco Inc. recently introduced a smokeless cigarette, but then withdrew it from the market. See RJR Nabisco Abandons 'Smokeless' Cigarette, Wall St. J., March 1, 1989, B1, col. 3.

9 J. Feinberg, Harm to Self 120 (1986). Garner accepts the strong substance caused view of addiction, and rests his case for requiring warnings on grounds similar to those of Feinberg. See Garner, supra note 3, at 1431-34. 
This analysis suggests that the decision to consume would be voluntary if the "drug taker" had a good "idea" that the drug was addicting generally or in his case-if the drug taker were appropriately warned.

This case for warnings is best grounded in the SSCV. According to it, the decision to begin consumption of an addictive substance is irrevocable for many users because physical withdrawal costs will preclude cessation. Hence, the consumption decision would "fall well below the requisite level of voluntariness" unless the maker of an addictive substance had issued a clear warning.

\section{B. Do Addictive Substances Exist?}

This case for requiring warnings supposes that some products have properties such that consumption of them by ordinary persons can become irrevocable. The difficulty is to identify the products that have these properties. Recall that to be addicted to a substance is to consume it to excess, not occasionally, but as a matter of routine. Many people obviously consume substances in this way. The question is whether their behavior is involuntary-caused against their will by the properties of a substance itself - or whether people prefer to consume certain substances to excess because this consumption pattern yields them pleasures in excess of pains. According to the strong substance caused view of addiction, an "addictive substance" induces persons involuntarily to consume to excess. The best recent discussion of this view, by Cass Sunstein, ${ }^{10}$ attempts to derive criteria for identifying the substances that do this. As is next shown, no known substances satisfy these criteria. If substances do not addict, the SSCV is false because it claims that addiction is caused by substances.

Sunstein defines an addictive product as one that a person would prefer never to be exposed to were he "armed with perfect information." "This does not get us far, but Sunstein adds that an addiction is "a process in which the subjective costs of not consuming a particular good increase dramatically over time, while the subjective benefits decrease or remain stable." ${ }^{12}$ The notion of stable benefits is inconsis-

10 Sunstein, Legal Interference with Private Preferences, 53 U. Chi. L. Rev. 1129, 1158-61 (1986). The analysis of Sunstein's view of addiction also applies to his view of habit, which he claims is similar to addiction "but it is less intense." Id. at 1161.

11 Id. at $1159,1161$.

12 Id. at 1158. 
tent with Sunstein's thesis, but his argument can dispense with stability. To see the difficulty, realize that a person will not begin consumption of a product unless the benefit from initial use exceeds its cost, which is primarily the product's price. If the price remains relatively stable, which is common, then if the benefit from each unit of consumption also remains stable, the user is never involuntarily addicted. This is because when marginal consumption benefits always exceed consumption costs, the user continues to consume not to avoid incurring physical withdrawal costs, but because consumption yields positive utility. Sunstein's belief that addictions are involuntary is rendered plausible by restating his position to provide that an addictive product generates physical withdrawal costs that increase with time and use benefits that decline strictly monotonically with time. After some period, the user of such a product would like to stop because consumption cost exceeds subjective benefit, but cannot stop because withdrawal cost is too great. One "armed with perfect information"- - one who could discount to present value the total costs and benefits of consumption over a life-would not voluntarily begin to use such a product unless he valued current utility much more highly than future gain. Uninformed persons, in contrast, might commence consumption and then be trapped. Thus, substances that generate the pattern of increasing withdrawal costs and monotonically decreasing use benefits are addictive.

Sunstein's definition is unsatisfactory because it is incomplete and, more importantly, because it implies predictions respecting addictive behavior that the facts disconfirm. Some notation will help make these difficulties clear. Let the cost of each unit of consumption of a substance equal the product's price, called $k$, and suppose that the price remains constant over the relevant time period. The product generates a unit of benefit $B$ with each use. Consumption of the substance is complementary over time, which means that the benefit that a user will derive from a unit of consumption today is affected by the fact that the user consumed the substance yesterday. Sunstein asserts that benefits decline with time, so letting $\mathrm{t}$ index time we can write $B=f(t)$ where $B^{\prime}<0 .{ }^{13}$ Ceasing to consume the substance will cause

${ }^{13} \mathbf{B}^{\prime}$ is the derivative of the benefit function with respect to time. In words, $\mathbf{B}^{\prime}$ is the marginal benefit of continuing to consume and is represented as negative because, according to Sunstein, the benefits from consumption decline as consumption continues. Id. at 1160 . 
the user to experience physical withdrawal costs $\mathrm{W}$; these are assumed to increase with prolonged use, so we can write $W=f(t)$ where $\mathbf{W}^{\prime}>0$. A necessary condition for beginning to use the product is that at $\mathrm{t}=0, \mathrm{~B}>\mathrm{k}$; the product generates initial benefits that exceed its costs.

Then there are two cases to consider. In both, the user first begins to use the substance at time $t=0$ and will die at time $t=T$. The rate at which the user discounts future benefits and costs to present value is d. At each moment the user has the choice whether to consume one more unit of the substance or incur the physical withdrawal costs entailed in discontinuing consumption. Also, in both cases the consumer has used the substance long enough so that the benefit of a unit of consumption $B$ has fallen below the cost of consumption $\mathrm{k}$. In case one, there exists a time $t^{*}$ such that $\int_{t^{*}} d(B-k)>W$. That is, $a$ user at $t^{*}$ who is then familiar with the substance's attributes will see that the net present value of continuing to consume the substance for as long as he lives (which is negative because $\mathrm{B}<\mathrm{k}$ ) exceeds the (also negative) costs of withdrawal; hence, the user maximizes utility by incurring the lower cost of discontinuance. This case can exist if marginal use benefits decline faster than withdrawal costs rise. ${ }^{14}$ The case also is consistent with Sunstein's definition, which requires only that benefits decline and withdrawal costs rise over time, but the products that this case describes cannot be addictive because people can stop using these products when they generate benefits that fall below their costs. The intuition underlying this result is simple: if the pleasure a particular substance provides declines relatively quickly while giving the substance up becomes difficult only after a considerable period of use, the substance cannot addict. Hence, the property of a product to generate declining marginal use benefits and increasing

14 Recall that benefits are assumed to fall and withdrawal costs to increase with time. If the former fall more rapidly than the latter rise, it is possible for there to be a time when the negative utility of continuing to consume--benefits minus constant consumption costsexceeds the negative utility of withdrawal. Consumption costs also include other people's disapproval and the inconvenience, when it exists, of pursuing one's habit. These costs probably do not increase significantly with time, so considering them would not contradict the representation of consumption costs as a constant. To add these costs would increase $k$ and so reduce the likelihood that particular products will addict. If cumulative use of a substance endangers health, as smoking cigarettes does, then consumption costs will rise with time. This case is considered infra Part III.B. The analysis in this Part holds if a rising consumption cost curve is assumed. 
physical withdrawal costs is a necessary but not sufficient condition for addiction.

The jointly necessary and sufficient conditions for addiction-the second relevant case-are (i) $\mathbf{B}^{\prime}<0$; $\mathbf{W}^{\prime}>0$; and (ii) $\mathbf{B}^{\prime \prime}<\mathbf{W}^{\prime \prime}$. Condition (ii) provides that the second derivative of the benefit function is less than the second derivative of the withdrawal cost function. In words, condition (ii) requires marginal use benefits to decline at a slower rate than withdrawal costs rise. When this pattern appears, it never will be the case that $\int_{{ }^{*}}^{\mathrm{T}} \mathrm{d}(\mathrm{B}-\mathrm{k})>\mathrm{W}$, so users cannot stop. Intuitively, if the substance provides pleasure for a long enough period, withdrawal costs will rise sufficiently so that they will exceed at every moment in time the (negative) net present value of continuing to consume the substance; hence, the user always maximizes utility by incurring the lower cost of continuing to consume. To use the common phrase, the user is hooked. Therefore, a product cannot be addictive unless it generates declining marginal use benefits and increasing withdrawal costs-condition (i); and the former fall more slowly than the latter rise-condition (ii). Products that satisfy both conditions will addict; products that satisfy only the first condition will not.

This formal statement of the SSCV generates three important predictions: (i) persons who are addicted cannot voluntarily quit; (ii) physical withdrawal costs are necessary to the causation of addictions; and (iii) addicts who are cured will seldom relapse. Respecting prediction (i), realize that physical withdrawal costs play a role in the theory that is analogous to an external physical threat. To see why, suppose that a person has decided not to drink milk anymore, but an evil member of the "milk establishment" threatens to inflict physical pain on this person so great that it would exceed her disutility from continuing to drink. Then the person will be a milk drinker for as long as the threat is credible, but her decision will not be voluntary. When the second condition for addiction derived above is met, a person cannot discontinue use of a substance, despite her desires, because cessation would cause physical pain-the withdrawal cost-that would exceed her disutility from continuance. This threat of incurring physical pain is credible forever because physical withdrawal costs are supposed to exist in consequence of substance-induced changes in the body's chemistry and nervous system. Therefore, a person who consumes a substance long enough to be addicted to it 
will always be addicted to it. Respecting prediction (ii), the theory holds that people continue to consume products that generate use benefits that decline below consumption costs only because physical withdrawal costs preclude cessation. Hence, products that produce no physical withdrawal costs cannot addict. Respecting prediction (iii), addicts can "detoxify" with the aid of drugs or by enduring with medical help the period of physical pain. Such cured addicts are, in Sunstein's phrase, "armed with perfect information" about the substance that addicted them, but no longer are coerced by the threat of incurring physical pain to continue using it. Hence, only addicts with unusually high discount rates or unusually short memories will relapse to addiction.

The facts reject these predictions. Respecting the first, people have altogether discontinued or substantially moderated their use of alcohol, tobacco, heroin, and other drugs. ${ }^{15}$ A review paper reports, for example, that some thirty million people have quit smoking, with ninety-five percent quitting on their own. ${ }^{16}$ Also, a large number of soldiers used heroin in Vietnam, but either discontinued use there or upon returning home, again with little apparent difficulty. ${ }^{17}$ This evidence suggests that allegedly addictive substances such as tobacco and alcohol do not generate physical withdrawal costs that are so high as to overcome the will of an ordinary person to discontinue use when

15 See Peele, A Moral Vision of Addiction: How People's Values Determine Whether They Become and Remain Addicts, 17 J. Drug Issues 187, 202-03 (1987). Peele's paper is a major literature review that cites 93 references. Similar evidence is found in the extensive review J. Orford, Excessive Appetites: A Psychological View of Addictions 271 (1985). Studies also show that people who relapse to smoking frequently return to abstinence. See Swan \& Denk, Dynamic Models for the Maintenance of Smoking Cessation: Event History of Late Relapse, 10 J. Behavorial Med. 527, 546-48 (1987).

16 See Office of Smoking and Health, U.S. Dep't of Health, Educ. and Welfare, Smoking and Health: A Report of the Surgeon General 32 (1979). The number of cigars sold annually is reported to have dropped from four billion in 1980 to 2.8 billion today. N.Y. Times, May 28 , 1988, at A29, col. 1. The recent Surgeon General's report also reports sharply decreased cigar consumption. Nicotine Addiction, supra note 4, at 580. Additional evidence that discontinuing addictive behavior is common is cited infra, notes 17 and 18 .

17 See S. Peele, The Meaning of Addiction: Compulsive Experience and Its Interpretation 110-11 (1985). The New York Times recently reported a major study by UCLA researchers entitled "Consequences of Adolescent Drug Use: Impact on the Lives of Young Adults." According to the Times, the study found that the "vast majority" of teenagers who experimented with alcohol and drugs at social settings were able to engage in casual use and not develop drug problems. N.Y. Times, July 21, 1988, at A1, col. 2. 
she comes to believe that the costs of consuming exceed the benefits. ${ }^{18}$ Also, if physical withdrawal costs do not preclude stopping, these substances may not generate declining marginal use benefits; people perhaps engage in long-term consumption because each use produces net gains. Respecting the second prediction, recall that an addiction consists in excessive appetitive behavior that is difficult to discontinue. This definition accurately describes the behavior of compulsive gamblers, yet persons can stop gambling without incurring physical withdrawal costs. Hence, the second prediction is disconfirmed also; physical withdrawal costs are not necessary to the causation of addictions. Respecting the third prediction, relapses to drugs, drinking, and smoking occur far more frequently than the SSCV predicts. Given that the facts disconfirm the three central predictions of the SSCV, the view likely is erroneous.

18 The recent Surgeon General's report on nicotine addiction claims that " $t]$ he pharmacologic and behavioral processes that determine tobacco addiction are similar to those that determine addiction to drugs such as heroin and cocaine." Nicotine Addiction, supra note 4 , at 16 . The chief physical withdrawal cost from ceasing to smoke is irritability. See Clavel, Benhamou \& Flamant, supra note 7, at 557. Persons who discontinue cocaine use also suffer irritability as well as depression and sleep disturbance. See Brower, Maddahian, Blow \& Beresford, A Comparison of Self-Reported Symptoms and DSM-III-R Criteria for Cocaine Withdrawal, 14 Am. J. Drug \& Alcohol Abuse 347, 351 (1988). The depression symptom, however, may result not only from the chemical properties of the drug, but also reflect a relapse to a former state; cocaine users often are depressive and apparently use the drug as a form of self-medication. See Mirin, Weiss \& Michael, Psychopathology in Substance Abusers: Diagnosis and Treatment, 14 Am. J. Drug \& Alcohol Abuse 139, 152-53 (1988). The apparent similarities among tobacco, heroin, and cocaine suggest that the existence of high physical withdrawal costs cannot explain continued use of these drugs. Additional evidence also shows that physical withdrawal costs from discontinuance of commonly abused substances are low. A recent review stated:

There is extensive evidence and growing recognition that withdrawal symptoms and tolerance only sometimes accompany addiction and are rarely its cause. . . .

Another strong indication that withdrawal symptoms and addiction are not always linked is that profound addictions often occur without withdrawal symptoms. For example, many researchers have found that a significant proportion of people who live the devastating lives of street junkies do not have withdrawal symptoms when heroin supplies are interrupted or when they are pharmacologically deprived by a "naxolene challenge."

In contrast, some drugs that produce withdrawal symptoms are not used compulsively. ...

Alexander \& Schweighofer, Defining “Addiction,” 29 Canadian Psychology 151, 155 (1988) (citations omitted). See also, e.g., H. Fingarette \& A. Hasse, Mental Disabilities and Criminal Responsibility 163-66 (1979). 
Before leaving this analysis, it will be helpful to anticipate the argument below by considering a possible modification of the SSCV. Suppose that addiction is a joint property of products and particular persons: some people are genetically capable of becoming alcoholics, and only these people experience the phenomenon of slowly declining use benefits and rapidly rising withdrawal costs from consuming alcohol. ${ }^{19}$ This modification also cannot explain why long-term addicts stop. So long as one's genes cause one to experience the defining phenomenon, one who is once addicted is always addicted. The phenomenon, however, is a part of the folklore of addiction; a person is believed to be an addict because she wants to stop using substances that no longer provide her with pleasure, but she cannot stop because the pain of withdrawal is too great. The inability of this pattern of costs and benefits to explain the evidence, even when supplemented with genetic theories, suggests that addiction is a function of more than products and biology.

The SSCV, if true, would support a case for requiring an addiction warning on the analogy to coercive threats: just as potential milk drinkers would want to know how the milk establishment behaves, potential users of a substance would want to know of the existence of physical withdrawal costs so high as would preclude cessation. Because these costs, however, account for little addictive behavior, the SSCV cannot ground a duty on the part of firms to warn that use of their products will of itself "addict." Part III pursues these legal implications in greater detail. Part II next considers other views of addiction.

\section{OTHER VIEWS OF AdDiction}

The SSCV is the only view of addiction to hold that certain substances can addict ordinary people involuntarily. This view founders on a large amount of evidence. The task then is to individuate addictions more precisely-to explain why some persons will become addicted to a particular substance but others will not. There are two candidate views of addiction that attempt this task, the biological view-only persons with certain biologies become addicted-and the characterological view-only persons with certain characters become

19 This modification transmutes the SSCV into a version of the BV. 
addicted. Part II argues that the latter view best explains addictive behavior.

\section{A. The Biological View}

A claim that addictions are a function of biology can take three relevant forms. To understand these forms, let $\mathrm{X}$ represent a particular person's biology and $\mathrm{A}$ an addiction to a particular substance. Then we have: (i) $X$ (in combination with taking the substance) is necessary and sufficient for $\mathrm{A}$-only persons with biology $\mathrm{X}$ can become addicted to the substance and every such person who uses the substance does; (ii) $\mathrm{X}$ is necessary for $\mathrm{A}$-only persons with biology $\mathrm{X}$ can become addicted to the substance, but not everyone who uses it does; (iii) $\mathrm{X}$ is neither necessary nor sufficient for $\mathrm{A}$, but is predisposing-members from the set of persons who lack biology $X$ and from the set of persons who have it both can become addicted to the substance, but those from the set with $\mathrm{X}$ will become addicted with a higher probability. The evidence concerning the relation between biology and addiction relates only to alcohol. It rejects the first two claims, but provides some support for the third. This Part argues that biological factors seem so weakly predisposing to alcoholism and so unlikely to be strongly predisposing to other addictions that the BV should be rejected as a basis for public policy.

It is helpful to begin with the alcohol evidence, of which there are three types to consider. ${ }^{20}$ First, certain biological abnormalities often are found in heavy drinkers. These abnormalities, called "markers," may play a causal role in alcoholism, but this role has not been traced. Also, nonalcoholics can have markers. That some alcoholics lack markers is inconsistent with claim (ii), that the markers are necessary for alcoholism; that some nonalcoholics have them is inconsistent with claim (i), that the markers are sufficient for alcoholism. Consequently, the markers can only be a predisposing cause. The relevant question is, by how much does having markers increase the probability that a drinker will become addicted? There now seems no answer. Second, alcoholics metabolize alcohol differently than

20 Much of the data in this paragraph derives from Fingarette, Alcoholism: The Mythical Disease, 91 Pub. Interest 3 (1988) and the review by Marlatt \& Baer, Addictive Behaviors: Etiology and Treatment, 39 Ann. Rev. Psychology 223, 227-28 (1988). See also H. Fingarette, Heavy Drinking 48-56 (1988). 
nonalcoholics do. It is unclear whether this difference is a cause or an effect of heavy drinking.

Third, a study of male children that had at least one alcoholic biological parent and that were put up for adoption shortly after birth claimed to show that eighteen percent of the children became alcoholic while five percent of men generally become alcoholic. ${ }^{21}$ This suggests a genetic component to alcoholism. Because eighty-two percent of the male children of alcoholics do not become alcoholic and men with nonalcoholic parents do become alcoholic, the genetic component also is a predisposing cause only. This study, however, is methodologically suspect. For example, the increased risk of alcoholism among the children of alcoholics was found only among those who had been diagnosed as "alcoholic"; no genetic loading was found among persons whose behavior fell into the categories of "heavy drinking" and "problem drinking." When these two categories are combined with the category of "alcoholic," the genetic contribution to alcoholism disappears. Since the likelihood of being diagnosed as an alcoholic correlates positively with engaging in behavior that falls into the latter two categories, the genetic explanation of alcoholism apparently needs further development. ${ }^{22}$ Later adoption studies claiming to find a genetic cause of alcoholism seem similarly flawed. ${ }^{23}$ If, nevertheless, there is a genetic component to alcoholism, then the question again is the amount by which genetics increase the probability that a drinker will become addicted. The adoption studies suggest that one is three or so times more likely to be an alcoholic in consequence of genetic factors, but this figure is less dramatic than it seems. The flaws in the studies from which the figure is derived impeach its seriousness. Also, since approximately four out of five persons with the genetic predisposition do not become addicted,

21 Goodwin, Schulsinger, Hermansen, Copenhagen, Guze \& Winokur, Alcohol Problems in Adoptees Raised Apart from Alcoholic Biological Parents, 28 Archives Gen. Psychiatry 238, 240 (1973).

22 See Searles, The Role of Genetics in the Pathogenesis of Alcoholism, 97 J. Abnormal Psychology 153, 158 (1988). This paper is a major review of the genetic/alcoholism literature, citing 84 references. The author found little methodologically sound support for the claim that alcoholism has a strong genetic component. For example, he says of several Swedish studies that also claimed to find a high heritability for alcoholism: "It is remarkable that the results of these studies have been accepted with virtually no critical examination." Id. at 159.

23 See id. at 161. 
something important other than biology is going on. ${ }^{24}$ Biological factors apparently have not been associated with other addictions.

This analysis raises two questions. First, what percentage of addicts were predisposed to this state by their biologies? Second, as just asked, among the addicts whose biology played a role, was biology actually a strongly predisposing cause? Current data seem insufficent to answer either question directly. This paper therefore pursues another strategy, to consider "indirect" evidence. One type of such evidence was cited above, respecting how many addicts are able to stop. This data does not impeach the biological view but clouds it. That so many people discontinue addictive behavior suggests that the ability to "conquer one's genes" is a common trait. This commonality in turn implies that biology does not strongly predispose a person to addiction. The second type of indirect evidence concerns other explanations for addictive behavior. If the data more strongly supports these explanations than it does the biological explanantion, this suggests that biology does not significantly increase the likelihood of addictive behavior.

To begin, cultural and social class explanations of addiction are plausible. Alcoholism is much more prevalent among Irish, Native American, and Black people, those of low social and economic status (SES), and men than it is among Asian Americans, Jews, medium and high SES persons, and women. ${ }^{25}$ Also, low SES people are more

24 A recent review paper, after discussing the idea of a genetic predisposition to alcoholism, stated:

[B]oth the nature of the physical and social environment and socialization experiences play a critical role in either exacerbating the risk or in protecting the vulnerable person from an adverse outcome. This relation between the person and the environment is both dynamic and reciprocal.

.. [P]ersonality can increase the risk for an alcohol or substance-abuse problem.

Tarter, Are There Inherited Behavioral Traits that Predispose to Substance Abuse?, 56 J. Consulting \& Clinical Psychology 189, 193 (1988).

25 The extensive evidence linking addiction and group differences is reviewed in Peele, supra note 15, at 189-94. There seems to have been substantial recent study of alcoholism among blacks. For a bibliography, see Watts \& Wright, Black Alcoholism, 33 J. Alcohol \& Drug Educ. 76 (1988). Also, George Vaillant and a collaborator recently presented evidence of a major longitudinal study of inner city English children of alcoholics (COA's). Forty-two percent of these children suffered in later life from alcohol abuse or dependence, as measured by DSM-III criteria, while $28 \%$ of an inner city control group developed these pathologies. The authors explained: 
likely than high SES people to smoke. ${ }^{26}$ This evidence suggests that cultural and peer pressures more strongly predispose persons to addictive behavior than do biological factors.

Another difficulty with the biological view is that addictive behaviors cluster. For example, apparently ninety percent of alcoholics smoke. ${ }^{27}$ Also, people who use one type of drug are very likely to use others; the full set of drugs such users ingest often is pharmacologically diverse, ranging from heroin to amphetamines and barbitu-

The COA's who developed alcohol dependence themselves had more alcoholism in their families and were raised in low SES families and in ethnic subcultures that at that time failed to help adolescents learn moderate drinking habits and failed to proscribe adult drunkenness. . . . [W]e are assuming that cultural background and SES were associated with familial attitudes toward drinking and intoxication. Passing on family attitudes towards alcohol may be one of the ways in which psychosocial factors modify the genetically influenced transmission of alcoholism.

Drake \& Vaillant, Predicting Alcoholism and Personality Disorder in a 33-year Longitudinal Study of Children of Alcoholics, 83 Brit. J. Addiction 799, 805 (1988) (citation omitted).

26 The American middle and upper classes to a considerable extent have substituted the consumption of health for the consumption of tobacco. The New York Times reports the observation of a lay but interested observer: "It's become unfashionable to do unhealthy things,' lamented Arthur Zartetsky, the owner of Famous Cigars at 55 West 39th Street, who complains that even marijuana seems more tolerated [than cigars]." N.Y. Times, May 28, 1988, at A29, col. 1. For more academic views, see Lau, Hartman \& Ware, Health as a Value: Methodological and Theoretical Considerations, 5 Health Psychology 25 (1986); Marsh, Smoking: Habit or Choice, 37 Population Trends 14 (1984). The recent Surgeon General's report on nicotine addiction stated that in the United States in 1985, 35.4\% of persons without a high school diploma smoked regularly while $16.5 \%$ of persons with postgraduate education smoked regularly. Nicotine Addiction, supra note 4, at 16.

27 See Istvan \& Matarazzo, Tobacco, Alcohol, and Caffeine Use: A Review of Their Interrelationships, 95 Psychological Bull. 301, $312-313$ (1984). See also Forney, Forney, Fisher, Richards, Scherger, Rixey \& Smith, Sociological Correlates of Substance Use Among Medical Students, 18 J. Drug Educ. 97, 99 (1988) [hereinafter Sociological Correlates] (Study found drug use "to be positively correlated with alcohol consumption and/or tobacco use."); Hansen, Graham, Sobel, Shelton, Flag \& Johnson, The Consistency of Peer and Parent Influences on Tobacco, Alcohol, and Marijuana Use Among Young Adolescents, $10 \mathrm{~J}$. Behavioral Med. 559, 575-76 (1987) ("[I]n many respects, tobacco, alcohol, and marijuana may be treated as equal contributors to a single drug use construct .... [T] he social psychological processes underlying the use of substances by youth have essentially the same characteristics .... [A] unitary concept of drug use among young adolescents is a viable one."); Marlatt \& Baer, supra note 20, at 225-26 ("[B]ecause of notions of biological/genetic specificity, disease models of addiction fail to account for commonalities among addictions, including addictions that do not involve substance use (e.g., compulsive gambling or sexual behavior).”); Newcomb, Fahy \& Skagner, Correlates of Cocaine Use Among Adolescents, 18 J. Drug Issues 327 (1988) (same results as in Sociological Correlates). 
rates. $^{28}$ Further, there is a generally positive correlation among the use of caffeine, tobacco, and alcohol. No biological model provides a plausible explanation of correlated use patterns. Specifically, these models seem unable to answer such questions as why, if one is genetically predisposed to drink, is one also genetically predisposed to smoke?

Finally, theories that focus on the contribution of personality factors to addictive behavior seem plausible. These theories help to explain the data respecting the correlated use of allegedly addictive substances. For example, if a person's personality predisposes her to consume to excess, it is improbable that she will consume only one thing in this way. Also suggesting that personality factors play a nontrivial causal role respecting addictive behavior, correlations among the behaviors of substance abusers extend beyond linked use. As an illustration, smokers are less likely to wear seat belts than nonsmokers and have higher accident rates. ${ }^{29}$ There is more direct evidence for the role of personality. The probability that a person will be a substance abuser correlates negatively with a strong sense of self-esteem, a desire to be in control rather than to take risks or seek thrills, being achievement-oriented, and being conformist respecting conventional moral norms. ${ }^{30}$ Studies thus show that alcoholics and other addicts

${ }^{28}$ See, e.g., Clayton, Cocaine Use in the United States: In a Blizzard or Just Being Snowed?, in Cocaine Use in America: Epidemiological and Clinical Perspectives (N. Kozel \& E. Adams eds. 1985).

29 See McGuire, Smoking, Driver Education and Other Correlates of Accidents Among Young Males, 4 J. Safety Res. 5 (1972) (accidents); Mechanic, The Stability of Health and Illness Behavior: Results from a 16-Year Follow-Up, 69 Am. J. Pub. Health 1142 (1979) (seatbelts); . There also is a correlation between gambling and substance abuse. See Lesieur \& Heineman, Pathological Gambling Among Youthful Multiple Substance Abusers in a Therapeutic Community, 83 Brit. J. Addiction 765, 769 (1988) ("The research reported here shows a clear connection between pathological gambling and substance abuse in two linked therapeutic communities.").

30 Much of this evidence is reviewed in J. Orford, supra note 15, at 110-25. See also Sutker \& Allain, Issues in Personality Conceptualizations of Addictive Behaviors, 56 J. Consulting \& Clinical Psychology 172, 180 (1988) ("Among the commonalities of addicted individuals is their penchant to choose with passion and sometimes with reckless abandon forms of satisfaction, escape, or change that are disapproved in American society and are associated with unfavorable consequences.") Id. at 180.

The view that addicts tend to be reckless or thrill seeking is supported by other researchers. See, e.g., Sociological Correlates, supra note 27, at 104-05:

Illicit drug, alcohol, and tobacco use are significantly interrelated. Forty-two percent of the current drug users in this study were also classified as heavy drinkers. Those involved in sensation-seeking sports and activities were more likely to be heavy 
have notably higher detection rates in psychological tests for antisocial impulsiveness or aggressiveness; in particular, they are more likely than the norm to indicate aggressiveness, assertiveness, pleasure seeking, sociopathy, and defiance of authority. ${ }^{31}$ Also, some studies show that the manifestation of behaviors synonymous with antisocial behavior in youth predicts later alcoholism. ${ }^{32}$ These data suggest that

drinkers. Overall, a pattern emerges that high-risk behaviors are correlated; a student will tend to be involved in more than one form of high-risk behavior.

See also, Craig, Psychological Functioning of Cocaine Free-Basers Derived from Objective Psychological Tests, 44 J. Clinical Psychology 599, 602 (1988) ("[T]he cocaine addict is characterized by acting-out traits, rebelliousness, has problems modulating anger, and shows moderate levels of depression and hyperactivity."); Johnson, Personality Correlates of Heavy and Light Drinking Female College Students, 34 J. Alcohol \& Drug Educ. 33, 34-35 (1988) ("Heavy drinkers manifested a greater fear of failure than did light/moderate drinkers. . . . The heavy drinkers were also significantly higher in sensation seeking . . ..").

31 See, e.g., Graham \& Strenger, MMPI Characteristics of Alcoholics: A Review, 56 J. Consulting \& Clinical Psychology 197 (1988). Similar personality differences apparently help to account for variations in smoking behavior. See Swan, Carmelli \& Rosenman, Psychological Characteristics in Twins Discordant for Smoking Behavior: A Matched-TwinPair Analysis, 13 Addictive Behaviors 51 (1988); see also Cox \& Klinger, A Motivational Model of Alcoholic Use, 97 J. Abnormal Psychology 168, 173 (1988) ("[C]ertain personality characteristics have been frequently observed among people who develop problems with alcohol. Characteristics such as nonconformity, impulsivity, and reward seeking are often seen both before the problems with alcohol develop and among alcoholics undergoing treatment."); Farrow, Personality Factors Associated with Driving While Intoxicated: A Comparison Study of Adolescent Drivers, 34 J. Alcohol \& Drug Educ. 21, 26 (1988) ("It would appear that DWI [driving while intoxicated] offenders and other adolescent offenders who drink engage in or endorse angry, hostile attitudes and behaviors distinct from those young drivers without DWI or other legal difficulty."). A recent literature review also found: "The results supported the hypothesized positive association between: alcoholism and drug abuse; alcoholism and antisocial personality disorder; and antisocial personality disorder and drug abuse." Schubert, Wolf, Patterson, Grande \& Pendleton, A Statistical Evaluation of the Literature Regarding the Associations Among Alcoholism, Drug Abuse, and Antisocial Personality Disorder, 23 Int'l J. Addictions 797, 801 (1988). Finally, in several studies of opium addicts the most commonly diagnosed personality disorder was "antisocial." See Craig, A Psychometric Study of the Prevalence of DSM-III Personality Disorders Among Treated Opiate Addicts, 23 Int'l J. Addictions 115, 120 (1988). The modal antisocial prevalence rate in these studies was $33 \%$. Id. at 121. Drug addicts, however, often have multiple personality disorders. See, e.g., id. at 118-19.

32 See Nathan, The Addictive Personality Is the Behavior of the Addict, 56 J. Consulting \& Clinical Psychology 183, 184-85 (1988). Antisocial behavior in youth and negative attitudes may predict a wide variety of excessive appetitive behaviors. See Clayton, supra note 28; Czechowicz, Adolescent Alcohol and Drug Abuse and Its Consequences-An Overview, 14 Am. J. Drug \& Alcohol Abuse 189, 195 (1988) ("the evidence of a positive relationship between childhood antisocial behavior and subsequent drug abuse is relatively consistent."). The claim in the text is not that a particular "addictive personality" exists and is revealed by standard psychological tests; rather, the point is that positive correlations between certain personality traits and addictive behavior are inconsistent with the view that genetic factors 
addictive conduct is part of a pattern of nonconforming behaviors.

In light of this evidence, the biological view seems implausible unless the propensity to engage in nonconforming behaviors itself has a biological-that is, inheritable-basis. There seems little evidence, however, that the personality traits that correlate positively with addiction are inheritable. Also, the conclusion that biological factors at most predispose persons to addiction would be unaffected by a showing that these personality traits are inheritable. This is because the behavior that evidences the traits is not always associated with addiction. $^{33}$

To summarize, the biological view holds that biological factors strongly predispose persons to become addicts. Biology is said to play this causal role because addicts differ physically from other persons or because the personality factors that contribute to addiction are inheritable. The view is implausible in either statement. There is little evidence that supports the idea that people are addicts primarily because they are physically different, nor is the notion of inheritable character traits well established. ${ }^{34}$ In addition, the plausibility of cultural explanations, the pattern of linked substance abuse behavior, and the contribution of personality traits, as manifested in responses to tests or as precipitated into observed behavior, all suggest that biology is at best a minor cause of addictions. ${ }^{35}$

strongly predispose persons to addiction, unless the personality traits themselves are inheritable.

33 Nathan, supra note 32, at 187.

34 Two leading authorities on addiction recently stated:

To date, however, the underlying biomedical mechanism of addiction has yet to be found, despite decades of diligent searching. New hope that the discovery is near is garnered by the use of sophisticated high-tech instrumentation and advanced technology .... . Modern technology may permit us to shine a brighter light into the body's physiological processes, but there is no guarantee that this will illuminate a biological key to addiction.

Marlatt \& Fromme, Metaphors for Addiction, in Visions of Addiction: Major Contemporary Perspectives on Addiction and Alcoholism 1, 6 (S. Peele ed. 1988) (citation omitted).

35 A recent analysis of addiction that may account for both excessive appetitive behavior and its cessation is in Becker \& Murphy, A Theory of Rational Addiction, 96 J. Pol. Econ. 675 (1988). This theory differs from the SSCV and the BV because, though it stresses the role of substances, it holds that people's personal characteristics-their time preference and age, for example-also determine whether they will become addicted. Becker and Murphy's main claim is that a necessary condition for a substance to addict is that "past consumption of the good raises the marginal utility of present consumption." Id. at 681 . This view helps to account for stopping, for example, because factors exogenous to the product can influence the effect of consumption over time, and so the product itself is not necessarily enslaving. The 


\section{B. The Characterological View}

The characterological view holds that some people choose to engage in excessive appetitive behavior because, given their characters and circumstances, substance abuse is an aspect of the best adaptation they can make to life. That addictive behavior is optimal given one's character implies that it is best viewed as voluntary. When a person acts in character, he is commonly considered to be acting freely. This common perception is held because people are partly responsible for their characters: one's character is in considerable part a function of one's desire to be a certain sort of person; also, one's character is partly constituted by her habits, which are built up from numerous discrete choices that, with repetition, harden into behavioral predispositions. ${ }^{36}$ It is character, on this view, that causes people to begin, to continue, and in many cases to cease engaging in excessive appetitive behavior. The CV seems best to explain the evidence respecting addictions.

Before reviewing this evidence, it will be clarifying to consider what it means to choose of one's own free will. Discussions of free will often draw distinctions among the kinds of desires a person has. An

theory, however, should confront two apparent difficulties. First, it "requires" that "strong addictions" end with a cold turkey quit, apparently because with a strong addiction the complementarity between present and future consumption is so great that only a little present consumption will much increase the utility of future consumption; consequently, an addict who tries only to moderate her behavior will inevitably spiral up into heavy use. Rather, the addict must quit cold turkey because, when present consumption ends, the marginal utility of future consumption necessarily falls to zero. The difficulty is that, as the citations above show, many people regarded as addicts do not stop altogether, but become moderate users. Becker and Murphy need a more precise definition of a "strong addiction" to account for this data. Second, just how past consumption increases the utility of present consumption is unclear in their theory. Becker and Murphy refer to a learning-by-doing effect, but this effect would seem to dissipate quickly; it doesn't take long to master smoking. Apart from learning by doing, the obvious link between past and present consumption is that one contemplating use today will remember past pleasures, but such memories seemingly can only cause present consumption, not affect its utility. Becker and Murphy's theory should show just how consuming yesterday influences the marginal utility of consuming today.

${ }^{36}$ Another way to put the claim in text is that a free choice is "in character, in the sense of choice that is a result of character traits which the agent affirms or accepts." See Brock, Paternalism and Autonomy, 98 Ethics 550, 563 (1988). The assertion that people choose their characters should be taken to hold in only a rough sense. This is because the assertion raises a regress problem: strictly speaking, one cannot choose a character trait without already possessing character traits with which to make the choice; but then the question is where these "preexisting" traits came from. The text thus asserts that persons choose their characters in the ordinary sense that people often come to possess, more or less, the characters they desire. 
effective first-order desire is a desire that actually moves a person to act. A "second-order volition" is a desire to have a particular set of effective first-order desires-a desire to want actually to do certain things for particular reasons when the time for action arises. In contrast to first-order desires, second-order volitions commonly derive from a person's conception of what is a worthwhile life to lead. ${ }^{37} \mathrm{~A}$ person exercises free will when he acts on first-order desires that are implied by his second-order volitions. Conversely, a person cannot act freely if he is powerless to implement his second-order volitions as effective first-order desires. This way of understanding what it means to act freely leads to a difficulty. ${ }^{38}$

Respecting this difficulty, suppose that a person says she wants to do action $\mathbf{x}$ in order to achieve goal $\mathbf{A}$; then her second-order volition apparently is to have an effective first-order desire to do $\mathrm{x}$ at the relevant time. At this time, however, the person is observed to do action $\mathrm{y}$, which is not implied by goal $\mathrm{A}$. There are two ways to explain this discontinuity between words and actions. First, this person's effective first-order desire was to realize the consequences of doing y. Because

37 The most influential version of this type of theory of free will is in Frankfurt, Freedom of the Will and the Concept of a Person, 68 J. Phil. 5 (1971) and Locke \& Frankfurt, Three Concepts of Free Action: II, 1975 Aristotelian Soc'y Systematic Study for Phil. Proc. 113 (Supp. vol. 49). The terminology in the text is Frankfurt's. For a recent review and criticism of this genre of free will theory, see Watson, Free Action and Free Will, 96 Mind 145 (1987). Watson notes that a person's second-order volitions sometimes may not derive from the person's notion of the good, but rather from what he thinks would be "fun, or thrilling." Id. at 150. Watson believes that this fact may make the notion of self-determination problematic, apparently because he believes that a person is not acting freely if he acts on a desire to have fun. Id. at 150 . It is unclear why he thinks this.

38 The free will literature, as will appear, does not discuss directly the difficulty that is set out next, but focuses on two others. First, the theory in the text is hierarchical, referring to an ascending set of desires. But then there is no reason to stop at two; a person could want to want to want to do something. Must acting freely entail a harmony among all possible levels of desire or only between second-order volitions and effective first-order desires? There seems no fully satisfactory answer to this question (Frankfurt himself takes the latter position). Frankfurt, supra note 37 , at 13. Second, this theory of free will has a difficulty with common intuitions about coercion. For example, a person could have an effective first-order desire to hand the money over to the armed mugger. This desire could be implied by a second-order volition to want to take the life-preserving action should one ever have a choice, yet most people would say that the victim was not acting freely in handing over the money but was coerced. Michael Slote argues that the victim in fact is not acting freely because he also had second-order volitions to resist unjust exactions and to protect his property; these volitions the mugger overbore. See Slote, Understanding Free Will, 77 J. Phil. 136, passim (1980). That hierarchical theories of free will are subject to the first difficulty and may be partly subject to the second does not affect the essence of the argument to be made next. 
she wanted to do y at the relevant time, she could not have possessed a second-order volition to want to do $\mathrm{x}$; had she had that volition, she actually would have done $x$ when the time arose. This person's true second-order volition therefore was to want to want to do $y$, perhaps in the service of goal B. A second possible interpretation of the person's behavior is that the person did have a second-order volition to do $\mathrm{x}$, but was powerless to act on it; when the time for action arose, she could not help wanting to do y, though at other moments she truly wants to want to do $\mathrm{x}$. The difficulty is to choose between these possible interpretations of the person's behavior. ${ }^{39}$

The free will literature speaks to this difficulty obliquely. The authors in it give examples of what unfree actions would be, and these examples commonly involve external causes. A person is powerless to implement her second-order volitions-she is unable effectively to want to do $\mathrm{x}$ when the time for action arises- because another person is manipulating her mind, often with the aid of electrodes magically implanted in her brain, to choose against her volitions; ${ }^{40}$ or she has been somehow conditioned not to want what her volitions tell her to want when she must act; ${ }^{41}$ or she is enslaved by addictive substances and so has an effective first-order desire to take drugs though her second-order volition is to refuse. ${ }^{42}$ If these examples exemplify unfreedom, then if a person is observed to act repeatedly in a fashion that is inconsistent with her expressed volitions, and if no external cause explaining this discontinuity exists, the person should be taken to be acting freely; she just has different second-order volitions than the volitions she expresses. Thus, one who claims to want to lead a life in which charity and helping others play major roles, but who never gives to charity and performs no public service, is considered hypocritical, not unfree.

39 Gary Watson sought to avoid the first difficulty with hierarchical theories remarked upon in note 38 , supra, that there may be many possible levels of desire. According to Watson, to act freely is just to have consistency between one's motivational and valuational systems-to act in accordance with one's values. See Watson, Free Agency, 72 J. Phil. 205, 215 (1975). One who holds to such a theory also faces the difficulty of explaining discontinuities between observed actions and professed goals.

40 See, e.g. D. Dennett, Elbow Room 8, 132 (1984); Fischer, Introduction: Responsibility and Freedom in Moral Responsibility 9, 9 (J. Fischer ed. 1986).

41 See Greenspan, Behavior Control and Freedom of Action, 87 Phil. Rev. 225, 226-34 (1978).

42 This is Frankfurt's standard illustration but many others use it. Frankfurt, supra note 37, at $12-13$. 
As just said, a substance could play the role of an external cause if the SSCV or the BV contained plausible causal accounts of the formation of addictions. These views do imply the possibility that a person could have a second-order volition to want to want not to smoke, but also have an effective first-order desire to smoke because of the "coercion" that physical withdrawal costs create. The implausibility of these views of addiction suggests, to the contrary, that a smoker who professes a desire to stop smoking actually does not have this desire among his second-order volitions. Rather, this person chooses to smoke of his own free will, his professed desire to stop expressing not a volition to stop, but rather the sincere wish that he were able to implement his true second-order volitions at a lower cost. The characterological view initially rests on this analysis; for it is prima facie plausible to suppose that addicts consume freely when they encounter no external factors that would overbear the will of a normal person. The plausibility of the $\mathrm{CV}$ is further enhanced by its ability to support more believable explanations of the actions of beginning, continuing, and ceasing to abuse substances.

Before assessing these explanations, a clarifying remark should be made about the role of circumstance. Holding character constant, persons are more likely to become addicted in some social situations than in others; the "setting" is a causal factor. ${ }^{43}$ The CV apparently neglects setting in its emphasis on the choosing individual and in its claim that addictions are best for addicts. One may respond to the $\mathrm{CV}$, that persons cannot always choose their social situations, and that what plainly would be best for some addicts would be never to have been in a social setting that conduced to addiction. This response is true but beside the point to be made here. For the CV holds only that an addiction is best for a person given her character and the circumstances in which life places her; nothing in the view is meant to imply that addicts are living an ideally good life for a person

43 See N. Zinberg, Drug Set and Setting 77-84 (1986) (finding "a high degree of association between opiate use and setting variables"); Mehrabian \& O'Reilly, Personality Correlates of Habitual Alcohol Use, 23 Int'l J. Addictions 175, 180 (1988) ("The present findings, and the related findings reviewed here, consistently indicated that settings that are conducive to boredom and loneliness (or a bored temperament condition) result in exceedingly high levels of alcohol consumption."). The evidence respecting the correlation between addiction and membership in certain cultural or social groups also evidences the role of setting. 
or that addicts are responsible in the fullest extension of that term for their current situations.

We turn next to how the CV explains addictive behavior. As regards beginning to consume excessively, a person who prefers to engage in antisocial behavior, or who is unafraid to engage in it, will likely try a variety of substances whose use society condemns. Similarly, a young person who believes he will do poorly in life may be undeterred from trying substances that are said to be pleasurable but also harmful because their use will impair his future chances. A person belonging to a cultural group that praises moderate, and does not strongly blame excessive, consumption of a substance is more likely than members of other groups to try substances that likely yield pleasure but sometimes are abused. The factors that cause all of these persons to begin also help explain continuance by those who find satisfaction in heavy use. ${ }^{44}$

44 The CV is similar to the "adaptive model" of addiction recently expounded by Alexander. See Alexander, The Disease and Adaptive Models of Addiction: A Framework Evaluation, in Visions of Addiction: Major Contemporary Perspectives on Addiction and Alcoholism, 45 (S. Peele ed. 1988). Alexander explains his model by referring to the predisposing cultural and personality factors associated with addiction that are summarized above. He then says:

These problems, and the way that the person understands them, result in failure to achieve the levels of self-reliance, competence, social acceptance, self-confidence and so on that are the basic expectations of society. In short, some people fail to "grow up" or to maintain adult integration.

Failure to reach or maintain adult integration. . . creates an urgent need to search out and choose substitute ways to provide meaning, organization, and social support. ... .

From an adaptive viewpoint, drug addiction or any other "substitute adaptions" are adaptive because the alternatives are worse. . . . In desperate situations, it is adaptive to choose the lesser evil.

Id. at 47 (footnote omitted). A similar model of addiction was suggested by Cox \& Klinger: [I]f a person does not have satisfying positive incentives to pursue or is not making satisfactory progress toward reaching goals that will produce positive incentives, weight will be added to that person's expectations that he or she can better enhance positive affect by drinking. Insofar as a person's life is burdened by noxious elements or he or she is making unsatisfactory progress toward removing these elements, weight will be added to that person's expectations that he or she can better counteract negative affect by drinking.

Prior research indicates, in fact, that drinkers act as if they choose alcohol to obtain particular emotional effects that they are unable to obtain through nonchemical incentives. They drink, for example, to feel more powerful, more womanly, more optimistic, and less anxious and depressed.

See Cox \& Klinger, supra note 31, at 174 (citations omitted). In a more succinct vein, Becker \& Murphy argue that although addicts may be unhappy, "they would be even more unhappy if 
The theory of "stimulus generalization"45 further illuminates consumption to excess. Under this theory, people commonly associate particular substances favorably with certain real world states or events: a beer feels great after playing a softball game, for example, so one chooses to drink beer after games. Stimulus generalization occurs when persons associate the substance favorably with several states or events: smoking is perceived to be pleasurable after a meal, when trying to concentrate on a difficult task, and then also when coping with a stressful morning, so one chooses to smoke on all these occasions. Persons may become addicted when they associate the pleasure that particular substances yield with so many real world states and events over a sufficiently long period that consumption becomes automatic and generalized; one does not consciously consider whether to smoke the next cigarette, but instead is a smoker. The stimulus generalization theory does not itself explain why some people generalize pleasures while others do not, but it is helpful in understanding aspects of the phenomenology of addiction. In addition to the analysis of the commencement of addictions just given, the theory helps explain why addictive behavior is more frequently associated with some substances than with others. Certain products, such as alcohol and cigarettes, are capable of providing pleasure and satisfaction in more settings than are other products, such as spinach and bran; products in the former category are more likely to be consumed excessively and will be more difficult to give up than products in the latter category.

The characterological view also helps explain how and why people moderate excessive appetitive behavior or cease engaging in particular behaviors altogether. The stimulus generalization theory guides therapies that seek to break the link users make between real world states and desired psychological states. Excessive eaters, for example, are encouraged to eat only at mealtimes. People are motivated to engage in forms of therapy or directly to alter excessive behaviors because they want to change their lives. Many men who drink heavily when young "mature out" of alcoholism, often voluntarily, because being an alcoholic is perceived to be inconsistent with job and family

they were prevented from consuming the addictive goods.” Becker \& Murphy, supra note 35, at 691 .

45 See Orford, supra note 15 , at 190-92 for a review. Fingarette develops a similar explanation. See Heavy Drinking, supra note 20, at 99-111 (heavy drinking is "a way of life"). 
responsibilities. ${ }^{46}$ Smokers commonly explain stopping as the product of a decision to change or get control over their lives. ${ }^{47}$ An important aspect of the phenomenology of addiction also is best explained by regarding cessation as a product of voluntary choice; therapy is efficacious but not differentially so. All alcohol therapies do equally well, for example, and none do better than an alcoholic's hour or two with a valued counsellor such as a priest. ${ }^{48}$ The similarity in results among different therapies and the success that many people experience with-

\footnotetext{
46 A recent review stated: "The few long-term prospective studies that exist indicate that most adolescents who drink heavily moderate their alcohol use in later life." Marlatt \& Baer, supra note 20, at 231. See also, e.g., D. Cahalan \& R. Room, Problem Drinking Among American Men 51-52 (1974) (Monograph reporting findings from two national surveys conducted in 1967 and 1969 and from a community survey of San Francisco in 1967-68, showing a rapid decline in drinking behavior between ages 20 and 30, and suggesting that problem drinking among young adults is a "temporary phenomenon.").
}

47 An interesting paper compared three groups attempting to stop smoking, one group on its own and the other two in different treatment programs. All three groups rated as the most important factor in stopping "self liberation"- the daily personal commitment to quit. See Di Clemente \& Prochaska, Self-Change and Therapy-Change of Smoking Behavior: A Comparison of Processes of Change in Cessation and Maintenance, 7 Addictive Behaviors 133 (1982). Marsh surveyed 2,700 British smokers and found that quitting required smokers to create a new set of beliefs that not smoking was itself a desirable and rewarding state to achieve. See Marsh, supra note 26, at 17. More recent studies confirm these results. One study compared the performance of persons attempting to stop smoking in treatment programs and on their own and found that the latter did better. The factors that best predicted success "appear to support the hypothesis that cognitions about health, locus of control, and selfefficacy are strongly associated with avoidance of relapse to tobacco smoking." Wojcik, Social Learning Predictors of the Avoidance of Smoking Relapse, 13 Addictive Behaviors 177, 179 (1988). Another study of smoking cessation found that persons who quit held stronger beliefs than those who did not about the desirability of good health and the ability to control one's life, and were more confident of their ability to resist temptation. Tipton, The Effects of Beliefs About Smoking and Health on Smoking Cessation, 122 J. Psychology 313, 318 (1988). Similar results appear for persons who discontinue or moderate excessive alcohol consumption. See Hermos, Locastro, Glynn, Bouchard \& de Labry, Predictors of Reduction and Cessation of Drinking in Community-Dwelling Men: Results from the Normative Aging Study, $49 \mathrm{~J}$. Stud. on Alcohol 363, 366-68 (1988); see also Canton, Giannini, Magni, Bertinaria, Cibin \& Gallimberti, Locus of Control, Life Events and Treatment Outcome in Alcohol Dependent Patients, 78 Acta Psychiatrica Scandanavica 18, 19, 21 (1988) (Individuals with an "internal locus of control"- those who feel that they are in control of themselves and their environments-present more favorable treatment outcomes than those with an "external locus of control"-those who see themselves at the mercy of fate and other forces.). Some smokers and drinkers apparently are able to acquire second-order volitions that imply effective firstorder desires not to consume excessively.

48 See H. Fingarette \& A. Hasse, supra note 18, at 175-86; Fingarette, supra note 20, at 19 20. 
out therapy suggests that the desire of the addict to change is the most important factor in getting straight.

The CV, in sum, can account for aspects of addictive behavior that other views of addiction have difficulty explaining. It helps to show why only some people become addicts, why some addicts can discontinue the use of addictive substances but others cannot, why some people engage in excessive and compulsive behaviors such as gambling and sex though they do not consume substances, and why some detoxified addicts often relapse to addiction. In each of these cases, being addicted, or not being addicted, is adaptive for the person involved. This way of putting the CV may make it seem tautological-people are doing what they want because people by definition do what they want-but the extensive evidence cited above, much of which is drawn from studies of individual addicts, refutes this charge. Also, when the CV is stated as an economic theory, it generates testable predictions that the facts so far confirm.

An economic analysis of smoking, for example, generates two sets of verifiable predictions. Initially, since ill health and early death are costs, an economic analysis predicts that cigarette consumption should decline as information about the dangers of smoking becomes better known. Such information first became widespread in the 1950's. A recent study estimated what per capita smoking consumption would have been and what percentage of the population would have smoked in 1980 had no information about smoking's hazards ever been made available and compared these hypothetical figures to actual 1980 data. Without information, per capita consumption for ages eighteen and over would have been 386 packs per year and $54.2 \%$ of the population would have smoked; in 1980, actual per capita consumption was 195 packs per year and $32.5 \%$ of the population smoked. ${ }^{49}$ Biological and substance caused views of addiction cannot explain why addictive behavior should moderate substantially in response to information about its hazards; a defining feature of these

49 See Ippolito \& Ippolito, Measuring the Value of Life Saving from Consumer Reactions to New Information, 25 J. Pub. Econ. 53, 62 (1984). The recent Surgeon General's report on nicotine addiction states that in the United States in $198532.7 \%$ of men and $28.3 \%$ of women smoked regularly. Nicotine Addiction, supra note 4, at 16 . The Ippolito analysis likely overstates the impact of new information on smoking activity because many people moderated their smoking not because they learned new things about it but because their tastes changed; they came to value good health relatively more and the pleasures of smoking relatively less. See supra note 47 . 
views is the belief that addicts cannot respond "rationally" to appeals to self-interest.

The second set of predictions rests on a more complex analysis. In contrast to the assumptions that underlie the SSCV, suppose that the benefits one obtains from an activity such as smoking initially increase and then level off; one first learns how to enjoy cigarettes and then derives about as much pleasure from smoking at forty as at thirty. ${ }^{50}$ A utility function that describes the pleasure one derives from smoking over time thus is concave. The cost to a consumer of smoking a cigarette- $\mathrm{k}$ in Part I.B above-now is assumed not to be constant. To perceive the shape of the "consumption cost curve" for smoking, suppose first that the benefits which a smoker derives from smoking exceed the monetary cost of cigarettes. Then, were there no health hazards associated with smoking, a person who began to smoke would never stop. This assumption is made both because it seems plausible and because it permits attention to be focused on the health hazards of smoking in an analysis of smoking behavior. There are two such hazards to consider. First, smoking shortens a person's life. Second, the effects of smoking can reduce the quality of life. If one begins smoking when young and quits by age thirty, the first cost apparently is zero; the life expectancy of people who quit by thirty and of people who never smoke is the same. ${ }^{51}$ The time necessary to dissipate the effects of smoking also is age related. If one quits when young, the effects of smoking are fully dissipated in nine or ten years, but these effects take up to twenty years to dissipate if one quits

\footnotetext{
50 Smoking is associated with reduced anxiety and a greater sense of self-efficacy. See, e.g., Gilbert \& Spielberger, Effects of Smoking on Heart Rate, Anxiety and Feelings of Success During Social Interaction, 10 J. Behavioral Med. 629 (1987). There is no reason to believe that the "units" of such benefits that a person derives from smoking a cigarette increase substantially over a person's life.

51 The evidence in the next two paragraphs derives from R. Arnott, F. Lewis \& N. Olewiler, Cigarette Smoking and Quitting: A Life-Cycle Approach (Discussion Paper \#709, Queens University 1988) (on file with the Virginia Law Review Association). These authors, in turn, rely largely on Hammond, Smoking in Relation to the Death Rates of One Million Men and Women, in Epidemiological Approaches to the Study of Cancer and Other Diseases 127 (National Cancer Institute Monograph 19, W. Haenszel ed. 1966) [hereinafter Hammond Study]. This is a useful data base both because it is very large and because many of the respondents began to smoke before social attitudes about smoking had changed; hence, the respondents may have been influenced by "purely" cost benefit factors.
} 
later. ${ }^{52}$ In the interim, these effects can influence health. The consumption cost curve thus is flat at zero for young people and begins to rise when people are in their thirties. The curve then declines for smokers in their sixties; by then so much damage has been done that the body cannot recover through abstinence in a typical smoker's expected remaining lifetime, so the health cost of further smoking falls substantially. An economic analysis holds that a person will continue to smoke until the marginal costs of quitting - the sum of the benefits that one who quits forgoes and the physical discomforts of withdrawal that he incurs-fall below the marginal costs of continuance.

This view generates three predictions of smoking behavior that are roughly consistent with the evidence. First, the optimal quitting age will vary from a smoker's mid-forties to her mid-sixties. Because the benefits that smoking provides, and thus the opportunity cost of quitting, level off over time, a curve that describes the costs of quittingthe QC curve in Figure I-should first increase and then flatten out. ${ }^{53}$ The rising consumption cost curve, beginning in a smoker's thirties, should begin to intersect the by-then relatively flat quitting curve sometime during these ages. In Figure I, a person thus smokes until time $t^{*}$, when the marginal cost of quitting and the marginal cost of continuance are equal; this point is reached when the QC and CC curves intersect. The evidence indicates that people do quit roughly in accordance with this pattern. For example, studies showed that, among males, in $1955,15.2 \%$ of the age cohort thirty-five to fortyfour were ex-smokers while $26.5 \%$ of the age cohort sixty to sixtyfour were ex-smokers; in 1983, the corresponding values were $42 \%$ and $57.5 \% .{ }^{54}$ Second, some people never will quit because their consumption cost curves reach a maximum before intersecting their marginal quitting curves; for such people, the cost of continuing to smoke has become largely historical and thus will not motivate quitting.

52 Apparently, the cost of smoking rises in one's thirties both because of the cumulative effects of smoking to this time and because the body then is more susceptible to the damage that cigarettes can cause and takes longer to dissipate this damage. See R. Arnott, F. Lewis \& N. Olewiler, supra note 51, at 8-12 analyzing data from Hammond Study, supra note 51 .

${ }_{53}$ The QC curve is the sum of two values, the benefits forgone from smoking and the physical costs of withdrawal discounted to present value should one decide in $t-i$ days to stop in period $t$. The curve is concave because consumption benefits level off and because withdrawal costs seem not to increase much after one becomes a smoker.

54 See R. Arnott, F. Lewis \& N. Olewiler, supra note 51, table 10. 
Figure I

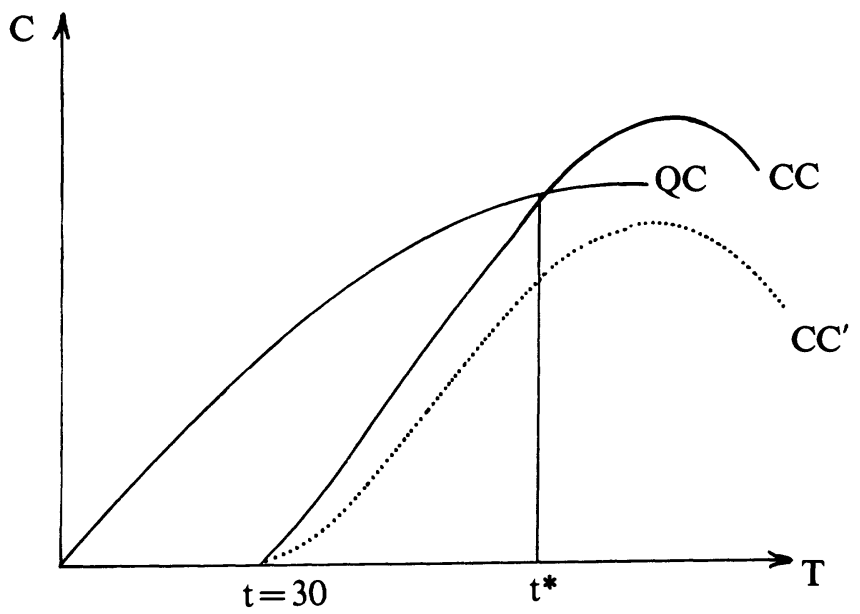

Figure II

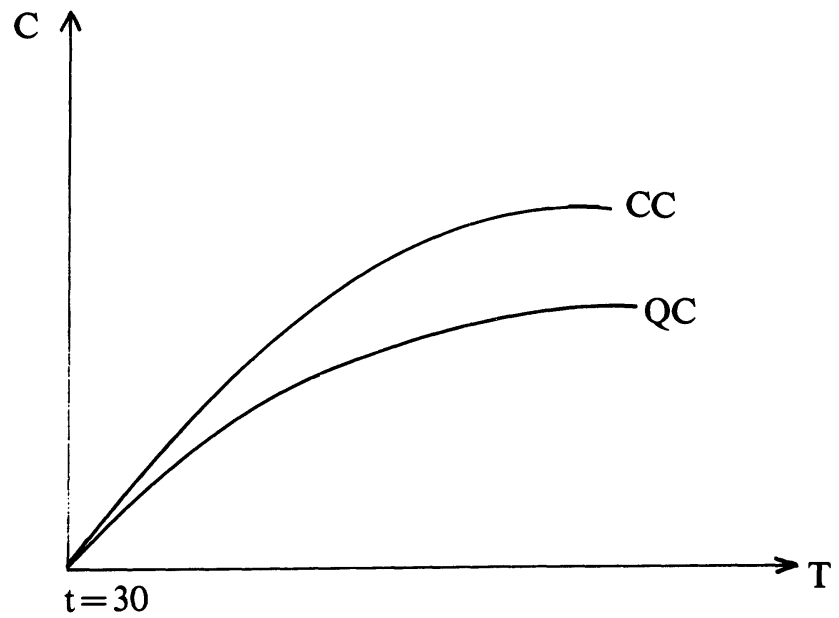


Figure I captures this phenomenon by drawing a $\mathrm{CC}^{\prime}$ curve that never crosses the QC curve. As is well known, some smokers never do quit.

Third, and perhaps less obviously, smokers are more likely to begin at early ages. When one is young, consumption cost is zero, so one will smoke if smoking generates any positive utility. The consumption cost curve begins to rise in a person's thirties. For some adults who contemplate beginning to smoke in their thirties, the (then increasing) consumption cost curve for smoking always will exceed the (also increasing) quitting cost curve; such persons never will begin. This phenomenon is captured in Figure II by showing a CC curve that always lies above the QC curve. Hence, a cross-sectional study of smokers should show that a larger percentage began early rather than late. Less than ten percent of the respondents in a major smoking study began after age twenty-four. ${ }^{55}$

Finally, if addicts were responsive to cost benefit considerations, such products as tobacco and alcohol would have price elasticities of demand that exceed zero. Studies confirm this prediction. The demand for cigarettes and liquor responds to price in the way that is predicted for other goods. ${ }^{56}$

The claim here is not that economists have fully explained the nature of addiction, but rather that addicts engage in maximizing behavior. The data support this claim because economic analysis assumes that people attempt to maximize expected utility. If an economic view of addiction predicts better than views that assume that people are enslaved by substances or their genes, then addiction likely is best understood with the aid of causal theories that make acting in accordance with one's will the major explanatory factor. ${ }^{57}$

55 See Hammond study, supra note 51 , at 128 , table 1 .

56 See Becker \& Murphy, supra note 35, at 686 (citing studies respecting the price elasticity of cigarettes); Coate \& Grossman, Effects of Alcoholic Beverage Prices and Legal Drinking Ages on Youth Alcohol Use, 31 J. Law \& Econ. 145 (1988) (effects of "substantial" price elasticity on probability of frequent drinking); Ornstein \& Hanssens, Alcohol Control Laws and the Consumption of Distilled Spirits and Beer, 12 J. Consumer Res. 200, 207-11 (1985) (demand is price elastic for distilled spirits but much less so for beer); and Saffer \& Grossman, Beer Taxes, the Legal Drinking Age, and Youth Motor Vehicle Fatalities, 16 J. Legal Stud. 351 (1987) (raising beer prices would substantially reduce number of fatal injuries).

57 Psychologists have recently done considerable research on alcoholism and substance abuse using a paradigm that is similar to the economic paradigm. According to the psychologists, alcohol and drugs are "reinforcers"; that is, they reduce a drive state existing in the organism. Psychological theory then predicts that use of a reinforcer will decline if constraints on its use increase. For example, use is predicted to decline if the amount of 
The characterological view nevertheless may seem implausible because it apparently fails to capture two defining features of addiction: the sense, shared by addicts and observers, that addicts are prisoners of their desires and the related sense that no one rationally chooses the status of prisoner. This apparent implausibility seems best dissolved by returning to the distinction between effective firstorder desires and second-order volitions. Character is importantly a function of second-order volitions: one chooses volitions that imply a preferred set of effective first-order desires-to want to want effectively to consume culture, to act as would a true friend and the like. On this view, being addicted never is knowingly chosen because one would never cultivate volitions that implied a first-order desire to abuse substances, to be prey, that is, to shameful but irresistable urges. This analysis is appealing, but is also consistent with the CV. Characters are not chosen all at once, but rather are acquired over time. In consequence, no one can choose her character-form a set of second-order volitions that together constitute a certain way of lifein the full awareness of all that the choice implies; a part of the wisdom one gains from living is a more complete understanding of the implications of possessing the character one has. Aspects of this understanding often are perceived as surprises: "I did not realize I was that sort of person" and the like. On the CV, some people come to learn that their characters and circumstances best imply a life in which alcohol, say, plays a major role. To quit thus entails altering one's character-one's set of second-order volitions-in such fashion

behavior required for consumption is increased. Also, use is predicted to increase if constraints on access to reinforcers that could substitute for the reinforcer at issue are increased. These predictions are similar to predictions from economic theory that consumption varies inversely with price and directly with increases in the prices of substitutes. A recent review of the experiments that sought to test the psychological theory, which cites 117 references, concludes that the theory has "considerable experimental support." In particular,

preference for alcohol (a) varies inversely with direct constraints on access to alcohol and (b) varies inversely with the availability of alternative reinforcers and directly with constraints on access to them. ... [T] he evidence with respect to the effect of direct constraints justifies a high level of confidence. Because these studies involved alcoholics and drug abusers in laboratory and clinical settings, as well as animals and nonclinical populations of humans, the generality of this variable for an experimental analysis of the determinants of alcohol abuse seems well established.

Vuchinich \& Tucker, Contributions from Behavioral Theories of Choice to an Analysis of Alcohol Abuse, 97 J. Abnormal Psychology 181, 185 (1988). These behavioral studies also support the view that addicts engage in maximizing behavior. 
that addiction is no longer implied. Altering one's character is sufficiently difficult that only some will do it. This way of putting the CV accounts for the two noticeable features of addiction referred to above: people in the short run are captives of their characters and do choose characters in ignorance of many of their important implications. But to say this is not to impeach the characterological view; according to it, people choose addiction freely given who they turn out to be and quit when they want to be different people. ${ }^{58}$ The evidence most strongly supports this view.

\section{Summary}

There are, broadly speaking, two conceptions of addiction. One holds that substances can induce addiction in ordinary persons-the SSCV - or in persons with particular biological predispositions-the BV. Both versions of this conception implicitly identify addiction with coercion. A substance, they claim, is addicting when (a) users rationally choose the negative utility of consumption (the substance no longer provides pleasure) rather than the greater negative utility of incurring physical withdrawal costs, and (b) the substance creates these physical withdrawal costs because they are a product of consumption-induced physical changes in users. The analogy to coercion is close. Just as the robber forces the victim to choose the negative utility of surrendering the money over the greater negative utility of incurring physical pain, an addictive substance forces its victim to choose the negative utility of excessive consumption over the greater negative utility that withdrawal would cause. Also, in both cases the victim's plight is traceable to an outside source: the robber is external and comes unasked; the substance is external in the sense that it causes the user's body to change, and it too comes unasked because the user begins to consume in ignorance and learns too late. These

58 Orford's book-length review of the addiction literature concluded its summary of the decision to quit with the observation:

Particularly with very difficult decisions, when attachment is strong and costs high, conflict is extreme and change involves not only high quality information processing but also self-reconstitution, the adoption of a new identity, a shift of attitudes and values across a wide range of issues. Change-supporting agencies have often taken a religious form.

Orford, supra note 15 , at 322 . Similar evidence is summarized more briefly in Marlatt \& Baer, supra note 20 , at $237-38$. 
defining features of an addictive substance explain why addiction is a paradigmatic example in the free will literature of a coerced choice.

The competing conception of addiction-the CV-rejects the analogy to coercion in favor of the view that addictions are chosen. According to this latter conception, a person is addicted to a product when (a) the utility of excessive consumption is positive; and (b) the user continues not because use entails incurring the lesser of two negative utilities, but because cessation would cause a high opportunity cost loss (which can only occur when utility from consumption is positive). To perceive the distinction between these competing conceptions of addiction, suppose that a person smokes because smoking reduces anxiety and produces a greater sense of self-efficacy, and these effects are felt for as long as tobacco is used. Then smoking always generates more utility for the user than not smoking. The primary cost of withdrawal is the emotional pain of once more feeling anxious and insecure. The use of tobacco, however, would not cause the former smoker to experience this pain; it will be felt because anxiety and insecurity are aspects of the smoker's preexisting character. There is, therefore, no outside source that coerces the smoker into retaining his addiction; rather, the addict chooses to smoke because smoking maximizes his utility-it best reduces his anxiety and insecurity-given who the addict is. To hold that a person is coerced because he makes a choice that his character implies is to deprive the word coercion of meaning. A person acts freely when he acts in character.

The evidence rejects the conception of addiction that underlies the SSCV and BV in favor of the CV. The normative implications of this conclusion are considered next.

\section{NORMATIVE IMPLICATIONS}

This Article asks whether courts should impose tort liability on firms that have failed to warn of the addictive nature of their products and whether the state should require firms, by statute or regulation, to add addiction warnings. Prudential and fairness considerations could dictate a negative answer to the first question while permitting a positive answer to the second. If firms are held liable in tort, society will incur the disruption costs of effecting enormous wealth transfers by common law litigation. As the asbestos and DES situations show, these costs are immense. Also, fairness questions are raised when very large retroactive sanctions are imposed. Neither prudential nor 
fairness considerations are germane when the question is whether the state should prospectively require firms to warn. As a consequence, evidence for particular views of addiction that is too weak to sustain common law liability could be sufficient to ground a case for statutory warnings.

Part III will show that the SSCV and BV both imply a case for warnings but the $\mathrm{CV}$ does not, supposing warnings to serve only the function of providing the information that a utility-maximizing consumer would need. Because the evidence supports the CV more strongly than it supports the other views, Part III's analysis, together with the prudential and fairness considerations just raised, implies that no good case for holding current firms liable for failing to warn exists. Part III argues that the case for statutory warnings is unpersuasive also, supposing the $\mathrm{CV}$ to be true, but plausible grounds exist to contest this conclusion.

\section{A. Warnings and the SSCV}

The SSCV would support a state-created warning that particular products "are addictive" were the view credible, but it is not. There is a case for state-created warnings that physical withdrawal costs are associated with the use of certain products, on an analogy to current drug warnings that use can create sleeplessness or irritability and the like. Firms that have failed to warn against these withdrawal costs also should be liable to former addicts who have incurred them, but the costs seem so slight that there probably will be few cases. The SSCV cannot support holding firms liable for the full set of costs associated with the living of an addictive life because it is not the consumption of products that causes people to lead such lives.

\section{B. Warnings and the Biological View}

The BV may better support a case for outright bans than for warnings. It holds that some people are strongly predisposed to become addicted to particular substances, in the sense that many of the people with the wrong biology will use these substances forever once exposed and that no one can stop without medical assistance or similar intensive third party intervention. Warnings thus seem helpful only to the extent that they permit potential users to sort themselves out; the warning will frighten off people with the wrong biology while the rest can go ahead. This is the case for warning people of drug side effects 
that only some users will experience, but such sorting is impossible when addiction is at issue. There is no way to know, by such means as a blood test or medical examination, who will abuse a particular substance; only use tells. The warning solution therefore prevents no evil and permits much. If a nontrivial percentage of the population is biologically strongly predisposed to become addicted to a particular substance, the substance seems better banned. ${ }^{59}$

This argument is less attractive than first appears because it fails to count the pleasure that use provides to the biologically safe. To perceive this, suppose that $\mathbf{n}$ percent of the population are so constructed biologically that they will become addicted to a substance; $(1-n) \%$ are able to use the substance in moderation and will derive considerable pleasure from it; and no one knows before use into which category she falls. Then there is a good case for a warning that discloses the odds. It is the case for permitting people who are informed of the risk to choose dangerous jobs: no one knows in advance whom such jobs will kill or injure; at best, the odds are known. But those who are not seriously injured or killed can pursue their most preferred life plan and the others are compensated for the risk in the wage rate. This argument does not turn on the size of $n$, though if $n$ is very large, it may be impossible to pay people enough to take the risk of using the substance. Then the substance will not be sold, but when choice is fully informed, the no-sale outcome is as consistent with a respect for autonomy as the sale outcome. Hence, the state should only require the makers of substances that addict subsets of users to disclose the odds.

This defense of warnings against bans is problematic if the state of being addicted is incommensurable. Disclosure that warns people against an outcome whose reality they cannot imagine is unhelpful. This problem may be serious because, apart from use, the best way to understand what being addicted means is to observe its effects, and young people, who are society's primary concern, may have seen too little of life. On the other hand, society lets young people volunteer for the military and work on suspension bridges. Is addiction less

59 The BV differs from the SSCV respecting addiction only in that, in the BV, a subset of users rather than almost everyone will be hooked by an addictive substance. Hence, if the BV supports a case for bans, the SSCV supports a stronger case since, if it is true, the relevant substance will harm more people. The relation between bans and the SSCV is not considered in text because the view itself is not credible. 
commensurable than death? Can this question be answered without making a normative choice among ways of life? Persons who value honor, courage, and being in control are more likely than bohemian pacifists to regard the choice to be a soldier as fully informed and the choice to consume heroin, even with a warning, as not. There is no obvious answer to the incommensurability problem. ${ }^{60}$

What can be said is that the biological view can support both cases for banning substances and for requiring warnings against their use, though it is difficult to choose between these strategies. The case for warnings will support a cause of action against firms for failing to give them. As shown above, though, the view that biological factors cause excessive appetitive behavior is too weak as a matter of fact to sustain this case.

\section{Warnings and the Characterological View}

\section{A General Analysis}

The characterological view does not support a case for warnings because warnings on the labels of addictive products would provide no useful information to persons who hold the correct view of addiction and likely would increase addictive behavior by the less informed. To understand the reasoning that generates these conclusions, suppose first that firms offer a set of products for sale denominated as $\{a, b, c, \ldots . . . n\} \in P$ and that only $c$ will hook people with the wrong characters. The set of consumers is $\{A, B, C\}$. The "A's" have addictive characters, the " $B$ 's" will derive pleasure from $c$ but be able to use it moderately, and the "C's" will derive no utility from $\mathrm{c}$ and not buy it again. The question is whether firms that sell $\mathrm{c}$ should accompany it with a warning that reads "This product is addictive." This phrase is referred to as "the minimal warning."

Begin in the context of a products liability suit and consider two cases. In the first, no one knows her character type, but that some people consume $c$ to excess is common knowledge. For example, suppose everyone knows that some people abuse alcohol. Requiring the

60 Society sometimes attempts a compromise among these positions by banning the sale of substances to children, but permitting their sale to adults with warnings. This solution is the more appealing the less plausible is the biological view of addiction; for, as the evidence with alcohol and tobacco shows, the solution permits substantial access by children to the substances in question. 
minimal warning seems pointless because it adds nothing to common knowledge; in the absence of the warning a potential consumer knows that she might or might not consume to excess, depending on her character, and she knows no more than this after receiving the minimal warning. Requiring a more detailed warning, such as a portrayal of the quality of a substance abuser's life, poses a disclosure task more complex than courts usually are asked to oversee. In this case, then, the firms should not be liable. This analysis itself may resolve the cigarette cases because apparently everyone knows that some smokers get hooked. It also may resolve these cases for one who accepts the biological view, if such an observer also believes that knowledge of the odds of a smoking addiction is widely held.

In the second case, no one knows her character type nor does anyone know which of products $a, b$, and $c$, if any of them, are used abusively. Firms that sell $\mathrm{c}$ should not be held liable for failing to give the minimal warning in this second case because, on the CV, there is no danger to be warned against. The CV holds that a person chooses to become addicted because frequent use of the substance is best for him, all in all, given who he is. To see what this view implies here, suppose first that the warning is given in connection with the sale of product c. Then everyone would consume the product if they held the characterological view of addiction. ${ }^{61} \mathrm{~A}$ potential consumer would know that she has either an $\mathrm{A}, \mathrm{a} \mathrm{B}$, or a $\mathrm{C}$ character. If she is a $C$, she will derive utility $\mathrm{U}_{0}=0$ from use because she will try the product once and stop. Let a $B$ derive utility $U_{1}$ from use where $\mathrm{U}_{1}>0$; moderate use is pleasurable. An A will derive utility $\mathrm{U}_{2}$ from use where $U_{2}>0$; addicts consume because long-term heavy use yields them pleasures in excess of pains. The illustrative consumer thus will buy at least once in face of the warning because, given these values, her expected utility from the purchase is positive.

Next, let the firms not warn. Then the consumer will know only that the product will addict her with probability $1 / \mathrm{P}$, but the choice to consume still has positive expected utility and so will still be made. The absence of a warning therefore will not influence a consumer's behavior. Sellers of product $c$ thus cannot have violated a legal duty by failing to warn because the sellers only withheld information that

61 The case against warnings seems strengthened if typical consumers hold either of the other two views of addiction. See infra p. 449. 
would have been valueless to the recipient. Another way to put this conclusion begins with the point that a warning against addiction is desirable only if potential users should be told that consumption will be difficult to conclude. But if use generates positive expected utility for everyone, cessation will be difficult only because it will entail forgoing pleasure. That there is an opportunity cost to giving up things one likes has never been thought to be the type of danger that firms should be required to warn against.

The analysis to here assumed that consumers know neither their characters nor which products are sometimes abused. Suppose that each consumer actually knows whether he is liable to consume to excess-whether he has an addictive character. Then those consumers who are "A's" would want to be told which products are abused because these products are best for them given their characters. Firms, however, do not wrong consumers by failing to advertise everything favorable about their products that any potential user may want to know. ${ }^{62}$ Hence, there apparently is no legal duty that firms violate when they fail to give the minimal warning against addiction, whether consumers know their characters or not.

It may be helpful to conclude this analysis by comparing the implications that the $\mathrm{CV}$ has for warnings to the implications that can be derived from the SSCV view of addiction for which the Ulysses and the Sirens legend is metaphor. In the story, Ulysses' most preferred life plan was to return home and he knew that he would be unable to carry this plan out without taking special measures; the Sirens would otherwise lure him and his crew to disaster. Hence, his choice was not to "consume" the Sirens' song - to put wax in his ears-or to use a precommitment strategy - to have himself tied to the mast-that protected against the adverse consequences of consumption. Circe had what today would be called a duty to inform Ulysses about the Sirens in consequence of their nature-that their song enslaved everyone.

Suppose instead that Ulysses was unsure whether he was the sort of person who would prefer to return home no matter what other

62 A beer manufacturer once advertised that "Schaeffer is the one beer to have when you're having more than one," apparently because market surveys showed that considerable beer was drunk by persons who seldom consumed one at a time. It has, however, never been claimed that the law should require firms to advertise the attributes of their products that are especially attractive to heavy users. 
options life offered or the sort who would prefer Sirens over home and family ties were he to meet with Sirens (in this CV-motivated modification, Sirens just provide pleasure, but occupy all of one's time). Ulysses knew that if he were the former type, he could tarry with Sirens if he met them but easily leave to enjoy the pleasures of home and hearth; and that if he were the latter type and it ultimately brought him insufficient joy, he could change to the former, though at a cost. This Ulysses has a different problem than the Ulysses of the legend. The Ulysses posited here knows ex ante that he will learn nothing new about Sirens when he meets them; he is well informed about Sirens. Rather, he will later learn something about his typewhether he is the sort who prefers Sirens in moderation or to excess. Thus, this Ulysses does not need to guard against making an ex post change of plan, resulting from a Siren-induced addiction, that he regards as unacceptable when viewed ex ante. His problem instead is to maximize his expected utility respecting Sirens conditional on his type. Indeed, if the characterological view of addiction is accurate, the notion of guarding against a change of plan is unintelligible as applied to persons who are well informed about the alternatives they will face.

Ulysses would find tying himself to the mast optimal in this version of the story only if the utility he would get from listening to Sirens just once exceeded the sum of the expected values from (i) the pleasures of visiting Sirens for as long as he liked were he a nonaddictive sort; (ii) the pleasures of living forever with Sirens were he an addictive sort, discounted by the probability that he will want to be addicted forever; and (iii) the pleasures of living with Sirens in an addicted state until he decided to alter his character, less the cost entailed in altering his character were he to turn out to be a Sirenpreferring type, discounted by the probability that he will want later to change to another type. ${ }^{63}$ If the cost of changing from a Siren preferrer to a home preferrer is no greater than the apparent costs of

63 For those who find a formal statement helpful, suppose that Ulysses is warned about Sirens. Let $\mathrm{U}_{0}$ be the utility of tying himself to the mast-of listening to the Sirens once. $U_{1}$ and $U_{2}$ are the utilities of contact with Sirens depending on whether one is a nonaddictive sort or an $A: U_{0}>0 ; U_{1}>0 ; U_{2}>0$. Let $q$ be the probability that one is an $A$ and $r$ be the probability that one who is an A will later want to change to a B at time t. Also, $d$ is Ulysses' discount rate; $\mathrm{e}$ is the relevant interest rate; $\mathrm{c}$ is the cost of changing his type; and he will want to change his type at time $t$ or never. Ulysses will walk the deck if 
withdrawal from such standard addictions as tobacco and alcohol, then the three pleasures, which together are the opportunity cost of forgoing all but one contact with Sirens, likely would dominate; an informed Ulysses would reject restraint.

Circe then had no duty to tell Ulysses that some people do choose to live with Sirens forever, were he ignorant of this fact. Such an unwarned Ulysses would not know that Sirens were addicting to susceptible sorts, but rather that Sirens with positive probability were a member of the class of things that do this. His expected utility from remaining free would still exceed the expected utility of restraint. ${ }^{64}$ Consequently, as said above, not to warn is to withhold from Ulysses no information of value; he will risk visiting Sirens whether warned or not because in either case the visit would yield him net expected benefits. The characterological view of addiction holds that this modified version of the Ulysses story best fits the evidence, and to accept this is to conclude that firms which omit warnings have not violated any legal duty and so should not be held liable. ${ }^{65}$

$$
\mathrm{d}\left\{(1-\mathrm{q}) \sum_{0}^{\mathrm{T}} \mathrm{U}_{1}+\mathrm{q}\left[(1-\mathrm{r}) \sum_{0}^{\mathrm{T}} \mathrm{U}_{2}+\mathrm{r}\left(\sum_{0}^{\mathrm{T}} \mathrm{U}_{2}\right]\right\}-\mathrm{d}(\mathrm{rc})>\mathrm{U}_{0} .\right.
$$

The three terms in braces are positive. These terms are moderate pleasure forever, addictive pleasure forever, and addictive pleasure until Ulysses wants to change. All three terms also exceed $U_{0}$ because $U_{0}$ is the utility of listening to Sirens just once. Therefore, unless withdrawal cost $c$ is very high in relation to the gains from use, the left-hand side of the inequality will exceed the right-hand side; an informed Ulysses would eschew the mast. The claim here is not that consumers always would solve such inequalities perfectly, but that warnings are unnecessary for people who are doing as well as they can. Warnings would not help people who make mistakes in calculations such as these because mistakes likely would be random, not always in a particular direction.

64 To perceive this clearly, recall that the expression to the left of the inequality in note 63 is the expected value of risking contact with Sirens when they are known to be addictive. Let this value be $\mathrm{E}(\mathrm{Ux})$. Then let $\mathrm{s}$ be the probability, for an unwarned Ulysses, that Sirens addict; if not, users derive utility $U_{1}$ from visiting them. Without a warning, Ulysses will reject restraint if $s(E(U x))+d(1-s) \Sigma_{0}^{\mathrm{T}} U_{1}>U_{0}$. If the first term on the left exceeds $U_{0}$, which the text assumes, then the entire expression exceeds $U_{0}$ because the second term is positive. Ulysses will reject restraint whether warned or not.

65 The Ulysses analysis suggests another possibility, that firms should warn potential users that the costs of character change probably are high. For the reasons given in Part III.C.4, infra, such disclosure cannot be made on product labels. Thus the failure to give it cannot ground tort liability. 


\section{Objections to the General Analysis}

Three objections to the conclusion that firms should not be held liable for failing to give the minimal warning against addiction deserve discussion: the lack of a minimal warning (i) forecloses common precommitment strategies; (ii) prevents a person from "choosing" her preferred addiction; and (iii) prevents a person from remaining ignorant of possibly unfortunate aspects of her character. These objections are interesting but unpersuasive. The argument respecting precommitment is best captured by an example: Let a person decide to consume ice cream only in restaurants and not at home, because were he to bring a container of ice cream home, he would be unable to resist eating all of it. Such a consumer would want to know that what he was buying was ice cream and not something else. This person's plight is not relevant here. Firms should be required to disclose what they are selling so people can pursue whatever consumption strategies they consider optimal. The issue is whether the label that reads "ice cream" should add, for the benefit of a first-time user, that ice cream "is addictive." This is unnecessary for the reasons above; a first-time user would buy the product whether warned or not, and the experience he gained through use would permit him to pursue precommitment strategies if he thought them best.

Respecting the choice of a preferred addiction, suppose (a) a person has a character that is prone to excess; (b) the set of adaptations she can make given her character has two members-she can be a smoker or a compulsive runner; (c) were she perfectly informed, she would choose to run; (d) the cigarette makers do not warn against addiction and the person first smokes; and (e) the choice of adaptations is path dependent - to choose to smoke forecloses or makes materially more difficult the choice to run. Under the regnant conception of warnings, which holds that firms should be required to warn only against defects in a product that could reduce a person's utility-that the product may cause cancer, say - there is no reason to warn this person. For all anyone can know, she will derive greater utility from a life as a smoker than from a life as a runner. There is a broader conception of warnings, which holds that a firm is required to warn against any nontrivial property of a product that some consumers might consider relevant. A product property that satisfies this criterion is that use may induce a choice of life plan that a well-informed consumer would reject ex ante. 
Even under this broader conception of the function that warnings should serve, there is no good cause for holding liable firms that fail to give the minimal warning. The crucial premise is (e) and it can be put in two ways. First, path dependence exists because substances are enslaving - this version is just the SSCV or BV and is unsound. Second, path dependence exists because the choice to consume certain substances changes preferences-one who smokes no longer wants to run. This formulation implies that premise (e) falls if preferences are stable-that is, invariant to the order of consumption. Then the person would try smoking and running and end up running because she prefers it, in the way people try liquor and wine and end up wine drinkers if they like wine best. If preferences are stable, trial and error will teach a person what suits.

When the issue is perceived to turn on the robustness of ex ante preference orderings to product experimentation, the path dependence objection to not requiring the minimal warning seems unpersuasive. This is not because path dependence never governs people's behavior; any serious choice of a way to live cuts off alternatives. The issue, however, is whether the choice to try such products as cigarettes and liquor is considerably more likely to alter preferences than other consumption choices that people routinely make. No theories except for the SSCV or BV give a positive answer to this question. The CV implies a negative answer, as does the evidence that many people sample tobacco, alcohol, and heroin and quickly give these substances up altogether or use them in moderation. Common intuitions are consistent with the $\mathrm{CV}$ and this formally gathered evidence. These intuitions suggest that it is less likely, for example, to "become a different person" after the first few smokes than to fall in love at first sight. Warnings are relevant only to initial users, however; after a time, persons have experience. The issue is empirical, but there seems too little evidence of strong path dependent consumption preferences to justify the imposition of common law liability for failing to warn, even under the broad function of warning law now assumed to obtain. ${ }^{66}$

66 This conclusion is not meant to deny that people sometimes adapt their preferences to the circumstances of their lives; it is sanity to try to like winters if one is compelled to live in Minnesota, and some people actually come to prefer them and refuse jobs in the South. The issue here rather is whether smoking a pack of cigarettes or taking some drinks will materially alter one's preference set. This seems less likely. 
The third objection to not requiring the minimal warning holds that some people suspect they may have addictive personalities but do not want to find out, and so would like to be warned away from addictive products. For example, a person suspects that he may become addicted to drugs if he ever has the chance, but does not want this fear confirmed; hence, he will not try-he is just strong enough to avoid-drugs that might addict. This consumer cannot pursue his consumption strategy unless the minimal warning is put on every product that a nontrivial set of buyers is likely to abuse. On the CV, addicts engage in maximizing behavior. Hence, this justification for requiring the minimal warning is unsound under the conventional view of warnings, which holds that warnings are meant to convey information about possibilities that are utility reducing. The broader view of warnings would support a different result, if a substantial number of consumers pursued such self-paternalistic strategies; these consumers would find the warning germane. The number of consumers who actually use these strategies seems too small to sustain this case for warnings.

In the short run, a person only can make better or worse adaptations to who he is; to adapt for the better is to maximize one's utility conditional on one's type. In contrast, to choose the strategy of remaining ignorant is to risk adapting for the worse because the posited consumption strategy permits the possibility that a consumer will eschew consumption patterns that are best for him given who he is. Some people do self-consciously pursue strategies that reduce the likelihood that they will make first-best adaptations to life, but there is little evidence that this is a common pattern. It seems unwise to incur the large costs that would attend the creation of a retroactive duty to warn just because a few people may prefer the strategy of actively concealing from themselves the characters they have.

\section{Requiring the Minimal Warning by Statute}

The analysis to here seems appealing in the context of lawsuits that have retroactive application but may be thought less persuasive when the issue is whether the minimal warning should be required by statute. Adding the minimal warning to a product's label would not be costly. Also, there is at least a chance that the BV or SSCV will turn out to be true, in which case the statutory warning may do some good. Further, there may be something to be said for the broader 
conception of warnings set out above, whereby firms should warn customers against all product properties that would affect the consumption choices of substantial subsets of users. Under this conception, the path dependence and concealing-one's-character-from-oneself objections to not requiring the minimal warning ultimately turn on the facts. The facts are not so conclusively against these objections as to make yielding to them in the relatively costless context of requiring statutory warnings a silly public strategy to pursue. There is, finally, a further function that warnings can serve, which is to express the state's view concerning the propriety of using certain legal products at all, or in particular circumstances. Under this function, the state could use the vehicle of requiring the minimal warning to make a symbolic, but helpful, condemnation of undesirable addictive behaviors. For example, to require the minimal warning on a cigarette package is to tell consumers that society permits, but does not respect, their decision to smoke.

All of these justifications for requiring the minimal warning by statute suppose that the only cost of the requirement would be to add a few words to the product's label. The justifications become questionable when it is realized that there are other likely costs. Initially, when the characters of people who do and do not become addicted are considered, and when some people's misconceptions about the nature of addiction are taken into account, a required minimal warning is likely to generate the wrong user mix. The warning would frighten away many people who are unlikely to become addicted because they value conformity, being in control, and succeeding as measured by common criteria, but who accept the SSCV or the BV. These people would lose the pleasure that moderate consumption brings. On the other hand, people with a propensity to engage in nonconforming or thrillseeking behavior would be more likely to use the product in consequence of the warning; they will take a warning as a dare or regard products with warnings as more alluring to them just in virtue of their having been identified as risky. ${ }^{67}$ Such users become addicts with a higher probability than the norm. In addition, to label a product

67 This insight is not new. For example, Romans 7:7-8 states:

Yet if it had not been for the law, I should not have known sin. I should not have known what it is to covet if the law had not said "You shall not covet." But sin, finding opportunity in the commandment, wrought in me all kinds of covetousness. Apart from the law sin lies dead. 
"addictive" may convey the impression that consumption will be intensely pleasurable, at least for a time. This too could increase use. These reasons suggest that requiring the minimal warning against addiction could increase it while making nonaddicts worse off. Finally, to describe a product as "addictive" could suggest to users who hold incorrect views of addiction that giving the product up is impossible or at least exceedingly difficult; efforts to change one's biology or fight truly enslaving substances may seem pointless. Hence, requiring the minimal warning could discourage attempts by addicts to change their lives.

Because addict populations are bad for society and because people probably would be better off were they not to possess characters that implied addiction, the likely consequences described here of giving the minimal warning are undesirable. The gains that may accrue from requiring the minimal warning by statute-for example, making a symbolic statement against addiction-seem too slight to risk experiencing these consequences. Therefore, if the characterological view is accurate, the minimal warning should not be required at all.

\section{Requiring A More Extensive Warning}

Requiring a more extensive warning seems impossible. There are four categories of information that potential users may find helpful. First, the consequences of consuming particular products to excess could be described in detail. Then people might be more strongly motivated to cultivate the kinds of characters for which addiction is a poor solution to life's problems. Here a distinction should be made. One set of dangers from excessive consumption is physical; long-term smoking, for example, causes cancer. It is possible and desirable to convey health-related data of this type; doing so is now often required. Another set of dangers from addiction entails living a blighted life, in which one cannot hold a job or sustain personal relationships and the like. Information of this latter sort seems better conveyed in schools and by moral instruction than through product labels; it is difficult to see how it could be conveyed on labels at all. Second, the type of characters that are strongly associated with addiction could be disclosed; the analogy is to drug warnings that caution

Recall also that addicts have a propensity to engage in thrill-seeking behavior and to act on antisocial impulses. See authorities cited supra, notes 30-31. 
against use by those with high blood pressure and the like. The analogy is weak because this form of disclosure is both pointless and offensive in connection with addictions. To put on a cigarette package the phrase "Do not use if you have a tendency to do rebellious acts that ministers condemn" is unlikely to reduce use by antisocial persons; to put on liquor labels the phrase "Do not use if you are Irish or poor" would be offensive as well as ineffectual. Too little is known about the precise personality characteristics and particular group affiliations that strongly predict addiction to create helpful and inoffensive "character disclosures" for product labels.

Third, disclosure of the costs of character change are relevant because consumers may know that there is a positive probability both that a product will hook them because of their characters and that they ultimately can escape by changing their characters. A fully informed choice to begin consumption would take into account the cost of making a later character change. The costs of making a character change, however, are primarily mental and emotional, and thus both vary considerably across persons and are highly nuanced. A product label is an insufficient medium for communicating information of this type. Only education concerning the costs and consequences of having and altering particular characters will help. Fourth, one would want to know what social circumstances conduce particularly to addiction. However, warnings against social settings"do not live in an inner city neighborhood"-would not be effective when put on product labels (or perhaps on anything).

In sum, because the product label is the policy clay that decisionmakers are constrained to shape, they can only fashion some version of the minimal warning. If the $\mathrm{CV}$ best explains addictive behaviors, no version of this warning should be required.

\section{CONCLUSION}

The question whether firms should be required to warn against the addicting properties of products turns on what one believes the primary cause of excessive appetitive behavior to be. The two most common views of addiction-of the causes of excessive appetitive behavior-are that some substances can enslave anyone who uses them and that some people's biology strongly predisposes them to become enslaved by particular substances. $\mathrm{A}$ third and different 
notion is that some people choose to be addicts because, given their characters, substance abuse provides them with pleasures that exceed the (often great) pains. These three conceptions are referred to above as the strong substance caused view, the biological view, and the characterological view. On either of the first two views there is a good case for warnings; people should be told that danger exists or at least be informed of the odds. The third view will not sustain a case for warnings initially because warnings would not influence consumption behavior for consumers who hold the characterological view of addiction. These consumers would know that to try an addictive substance would yield positive expected utility whether they ultimately consume moderately or to excess; hence, they would try were they warned. To fail to warn them thus cannot violate a legal duty. Put another way, if consumption yields net expected gains and withdrawal entails incurring slight physical costs, then ceasing to consume will be difficult only because it will entail foregoing positive utility. Warnings against opportunity costs of this kind never have been required. For consumers who hold either of the other two views of addiction, warnings will be harmful rather than innocuous; they likely will encourage use by those who should abstain, frighten away users who would benefit, and discourage addicts from changing their characters.

Warnings against such commonly abused products as tobacco and alcohol should not be required because the evidence shows that the characterological view of addiction best explains what is known about it. Nor should firms that sell these products without warnings against addiction be held liable in tort. These conclusions do not imply that the state has no role to play. According to the values most people hold, to be addicted is to possess an unfortunate character. It is legitimate for the state to provide instruction in how characters are formed and in the consequences to which the possession of particular characters gives rise, and to assist those with few means and a bad habit to attempt character change. Also, some addictions that are optimal for the addicts are sometimes associated with undesirable behaviors, such as ruining family lives or committing crimes, that the civil and criminal laws cannot adequately deter. Addicts too are said to make excessive use of publicly provided health and welfare services. When the negative externalities that are associated with a particular substance plausibly outweigh the benefits consumption provides to addicts and 
nonaddicts, there is a prima facie case for banning the substance. In sum, the state can respond to the problem of substance abuse with good and bad strategies; to require warnings is to choose a bad strategy. 